\title{
PERFIL SOCIODEMOGRÁFICO DE LOS INTERNAUTAS
}

ANÁLISIS DE DATOS INE 2020
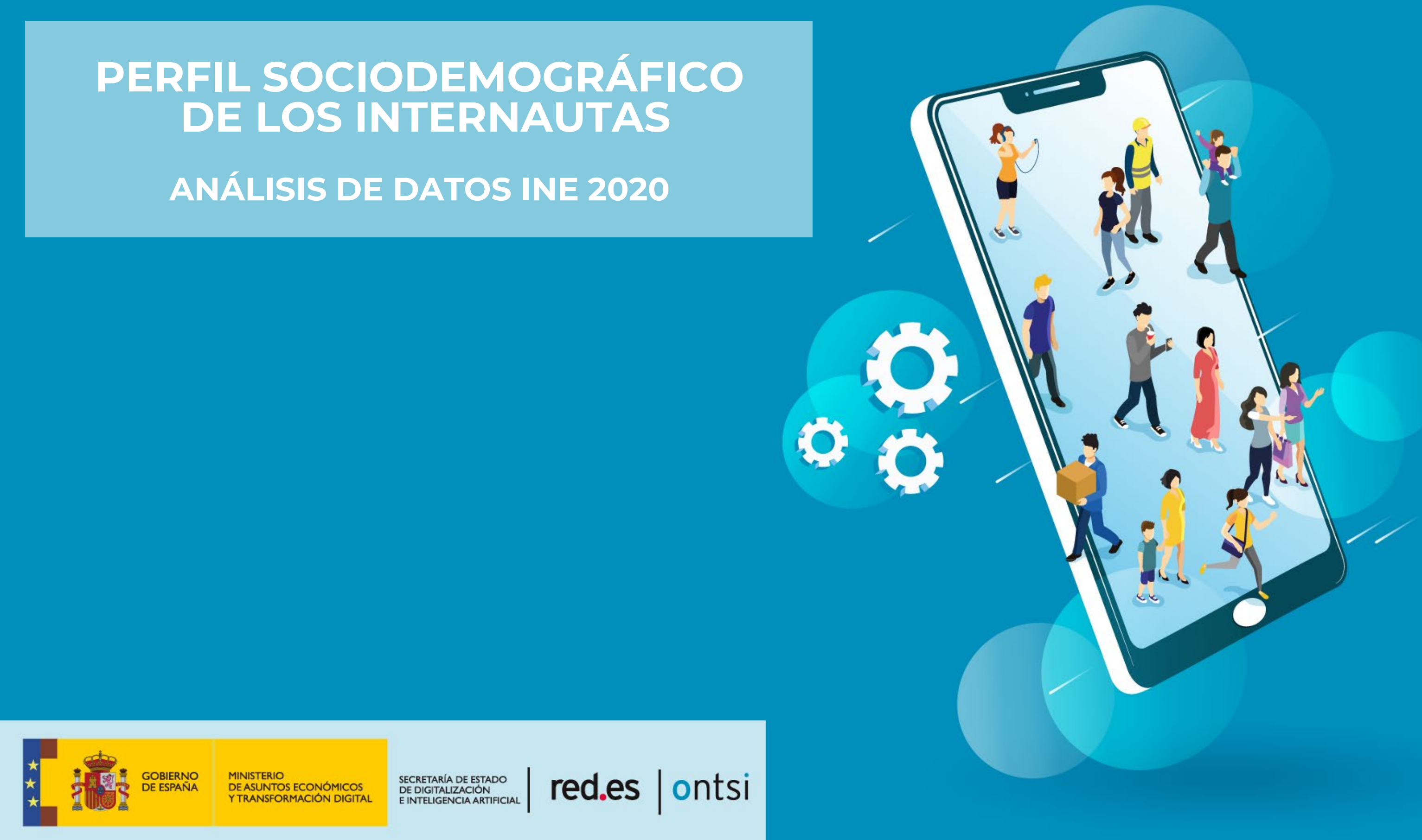
El propósito de este trabajo -basado en el análisis de microdatos de la Encuesta TIC Hogares del INE- es caracterizar la evolución de la población internauta de España (acceso a Internet, tipos de usos, ...) en función de distintas variables tales como el sexo, la edad, el nivel educativo, la renta o el lugar de residencia. Con ello se pretende proporcionar una radiografía de cuáles son los segmentos en los que se debe incidir para reducir la brecha digital.

Además de las características sociodemográficas de los internautas -según frecuencia de acceso a la Red y los diferentes usos que realizan-, se analiza la evolución de estas variables en los últimos años.

Como novedad en el estudio de este año, se ha realizado un análisis sociodemográfico de la población española en aspectos como la confianza, seguridad y privacidad en Internet y en los usos de la ciudadanía en el ámbito del "Internet de las Cosas".

El anexo final recogen la evolución detallada de la utilización de Internet por segmentos sociodemográficos.

El "Perfil sociodemográfico de los internautas. Análisis de datos INE", se realiza en virtud del convenio con el Instituto Nacional de Estadística. 


\section{ÍNDICE}

1. Número de internautas y frecuencia de uso

2. Uso de Internet por características sociodemográficas

3. Distribución sociodemográfica de la población internauta

4. Evolución del porcentaje de internautas

5. Protección de datos, seguridad en Internet e loT

6. Anexo y ficha técnica 


\section{Número de internautas y frecuencia de uso}

2. Uso de Internet por características sociodemográficas

3. Distribución sociodemográfica de la población internauta

4. Evolución del porcentaje de internautas

5. Protección de datos, seguridad en Internet e loT

6. Anexo y ficha técnica 
En 2020, 37,3 millones de personas de 10 y más años ya han accedido a Internet en alguna ocasión, la gran mayoría (91,3\%) accedieron en los últimos 3 meses. Entre los/as niños/as de 10 a 15 años se ha producido un incremento interanual de internautas del $3,1 \%$, alcanzando los 2,8 millones

2018

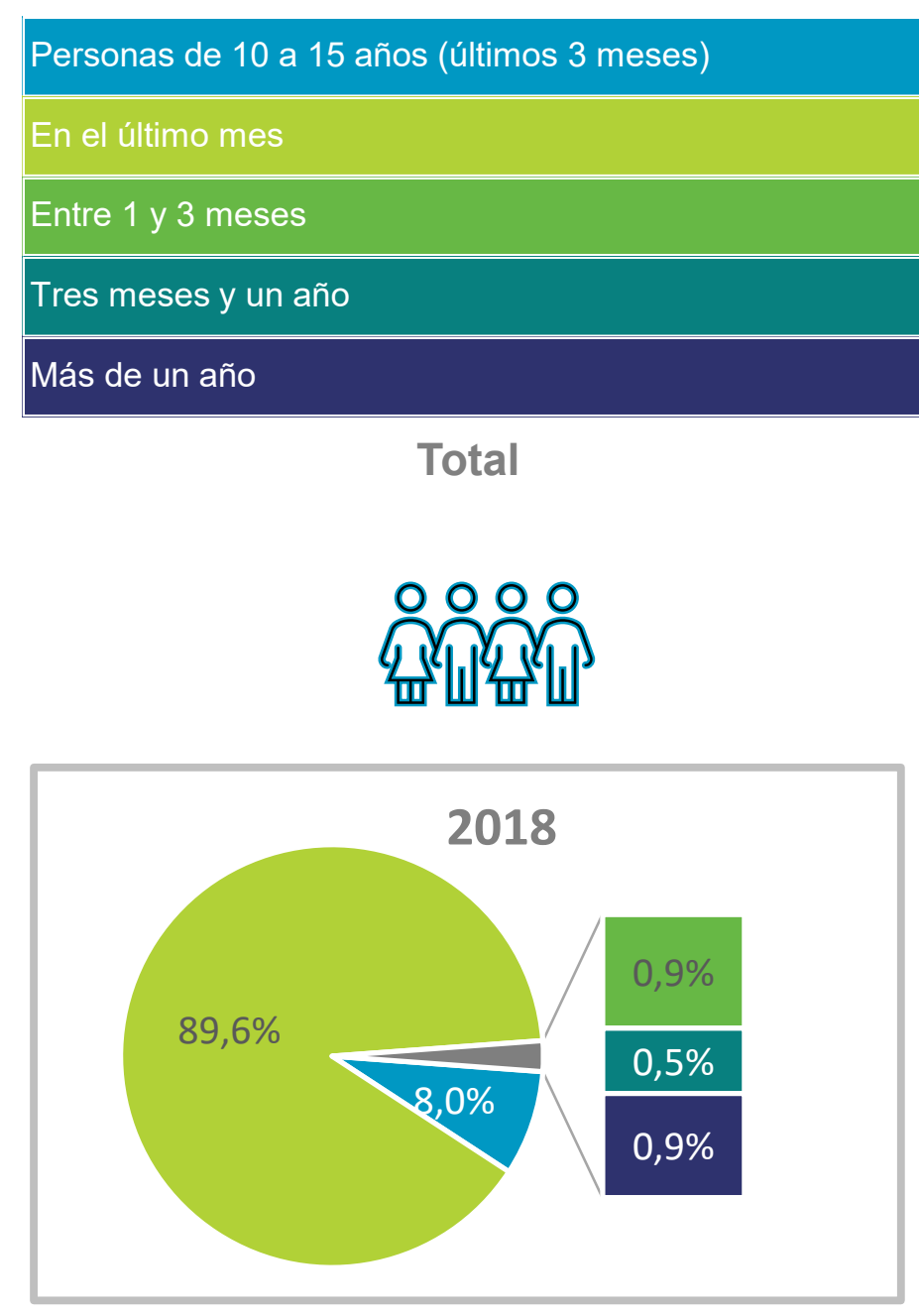

2019

\begin{tabular}{|c|c|c|}
\hline 2.710 .437 & 2.779 .695 & 2.865 .355 \\
\hline 30.203 .087 & 32.482 .984 & 34.054 .092 \\
\hline 316.627 & 180.042 & 122.174 \\
\hline 182.310 & 113.162 & 260.621 \\
\hline 290.072 & 262.988 & 37.302 .241 \\
\hline
\end{tabular}

33.702 .533

35.818 .871

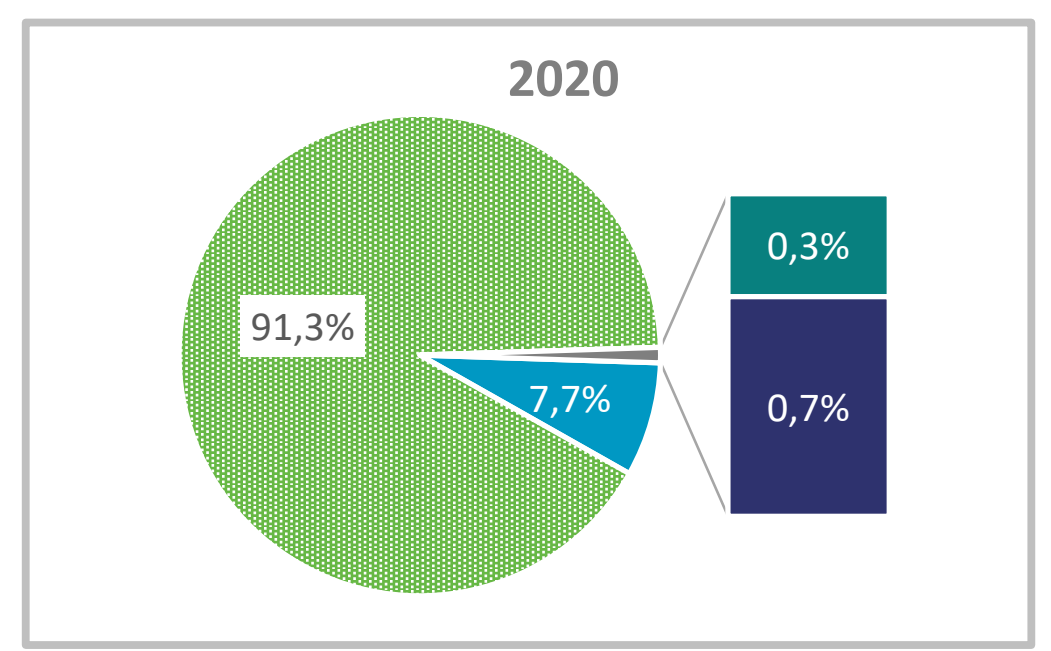

กำำกำ 
El 93,2\% de las personas entre 16 y 74 años ha accedido a Internet en los últimos tres meses. Ocho de cada diez se conectan diariamente, lo que corresponde a casi 30 millones de personas. Por otro lado, un $6 \%$ de población nunca ha utilizado Internet, aunque este porcentaje se ha reducido 2,4 puntos porcentuales en el último año.

Población española de 16 a 74 años

\subsubsection{8}

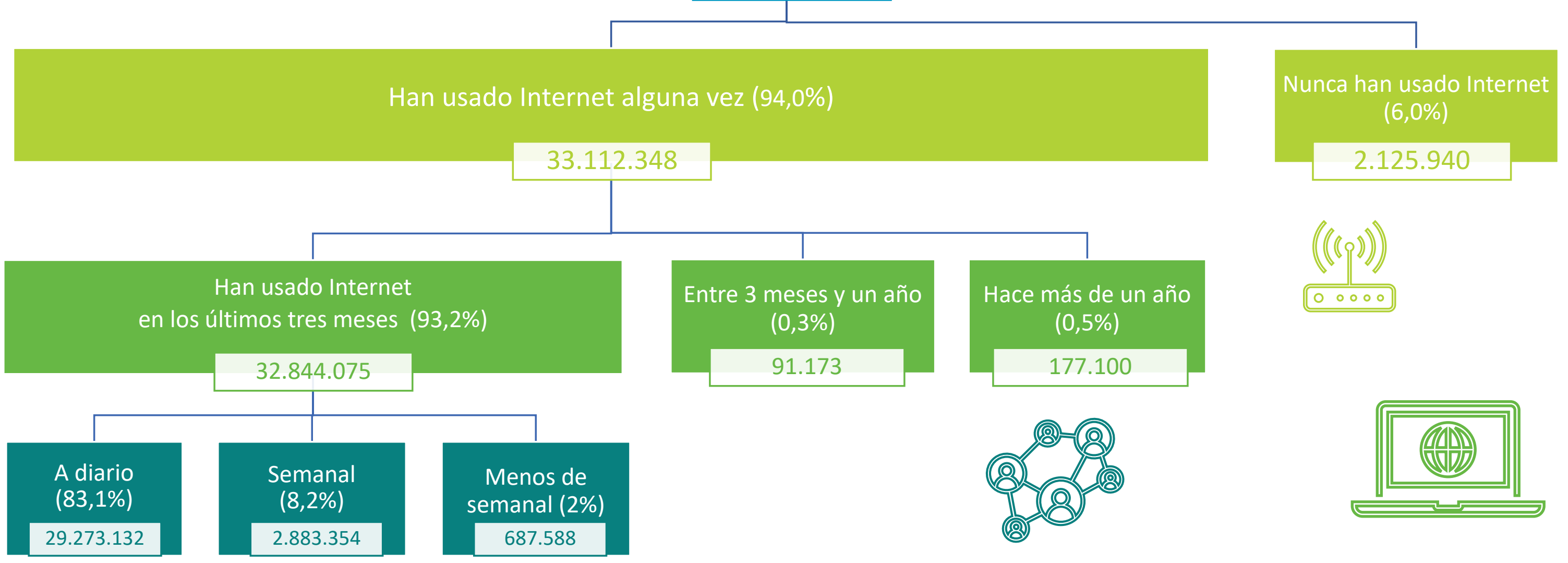


1. Número de internautas y frecuencia de uso

\section{Uso de Internet por características sociodemográficas}

3. Distribución sociodemográfica de la población internauta

4. Evolución del porcentaje de internautas

5. Protección de datos, seguridad en Internet e loT

6. Anexo y ficha técnica 
La variable género no marca diferencias significativas en cuanto al uso de Internet.

El $94,2 \%$ de hombres se ha conectado en alguna ocasión mientras que este porcentaje se sitúa en el $93,8 \%$ en el caso de las mujeres. La frecuencia de acceso semanal ronda el $91 \%$ tanto en hombres como en mujeres.

El uso de la Red es más frecuente entre la población joven y de mediana edad, con valores por encima del $85 \%$ en el caso de conexión con frecuencia semanal y del $97 \%$ en el caso de acceso en alguna ocasión.

Entre la población de 65 a 74 años los porcentajes se reducen hasta el $64,3 \%$ en cuanto al acceso semanal y al $72,4 \%$ al considerar el acceso en alguna ocasión.
Porcentaje de internautas en cada categoría por género (\%)

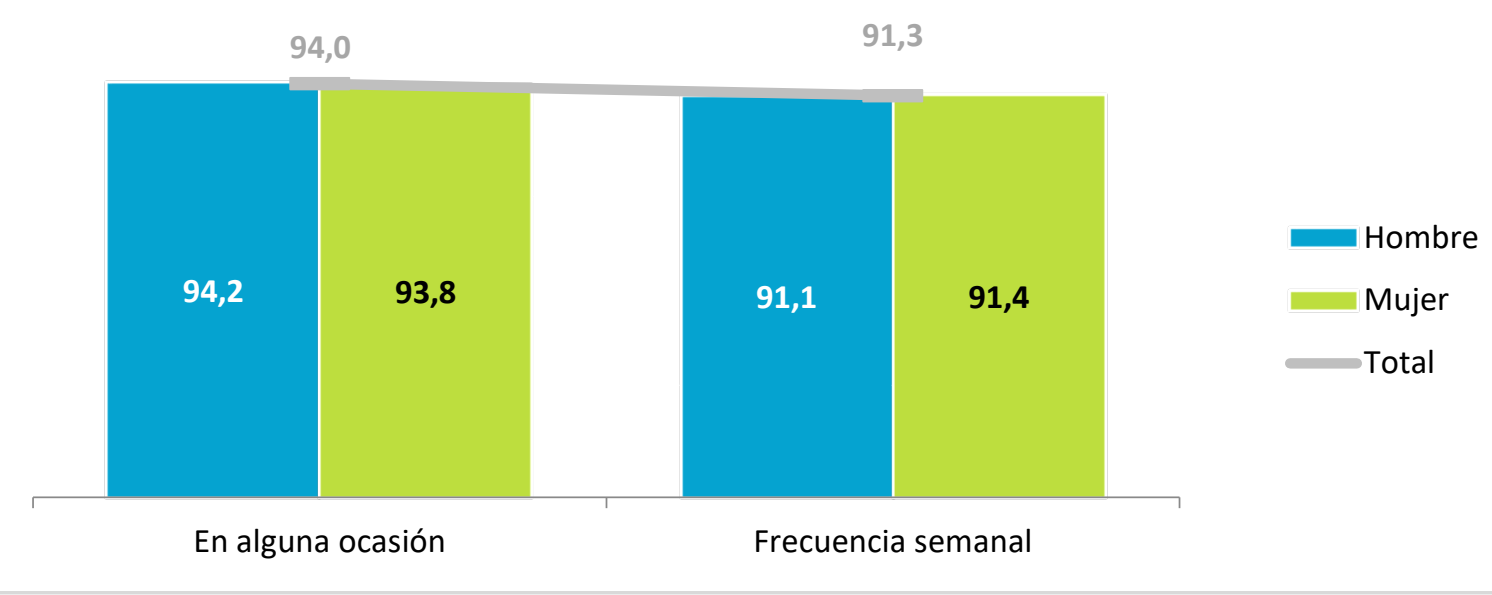

Porcentaje de internautas en cada categoría por edad (\%)

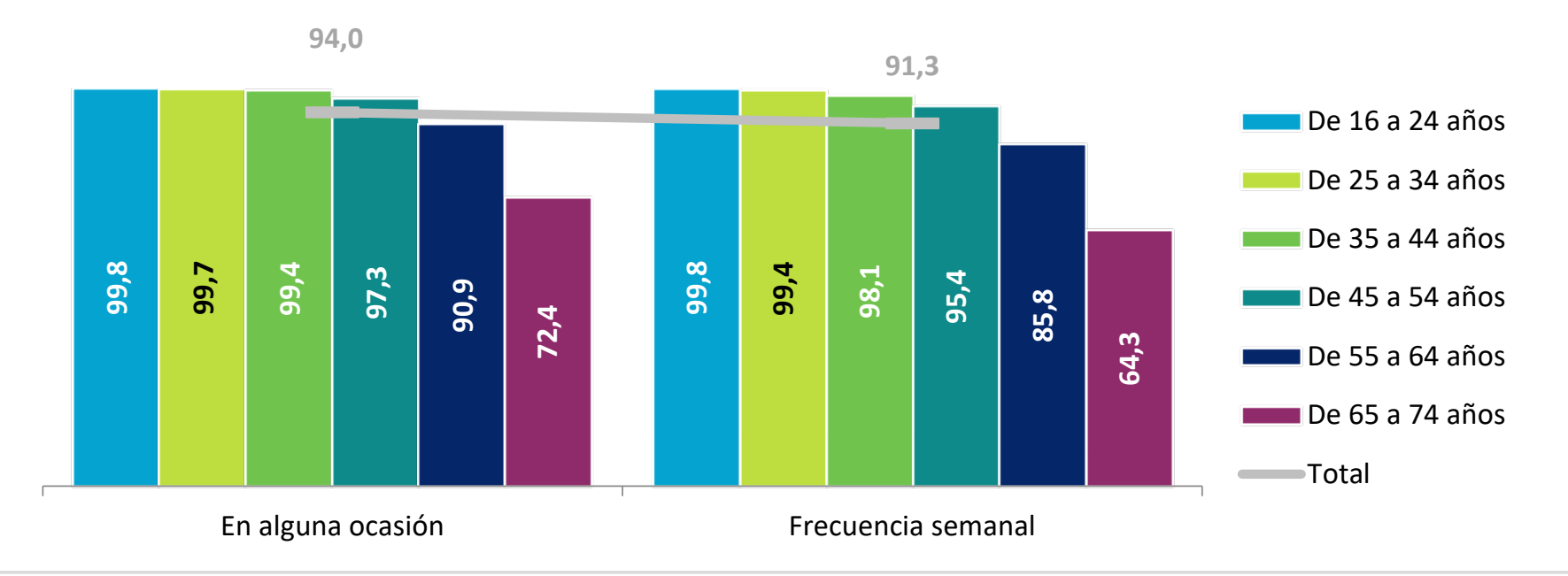


Las personas ocupadas, paradas y estudiantes, son los que tienen mayores porcentajes de internautas, todos por encima del $90 \%$.

Aun así, dos de cada tres pensionistas se conectan semanalmente y tres de cada cuatro accedieron a la red en alguna ocasión.

El nivel de estudios alcanzado también muestra algunas diferencias significativas, principalmente entre las personas con educación primaria y aquellas con educación secundaria o superior.

Siete de cada diez personas con educación primaria, se conectan semanalmente a Internet, mientras que este porcentaje es prácticamente del $100 \%$, en personas con estudios universitarios.
Porcentaje de internautas en cada categoría por situación laboral (\%)

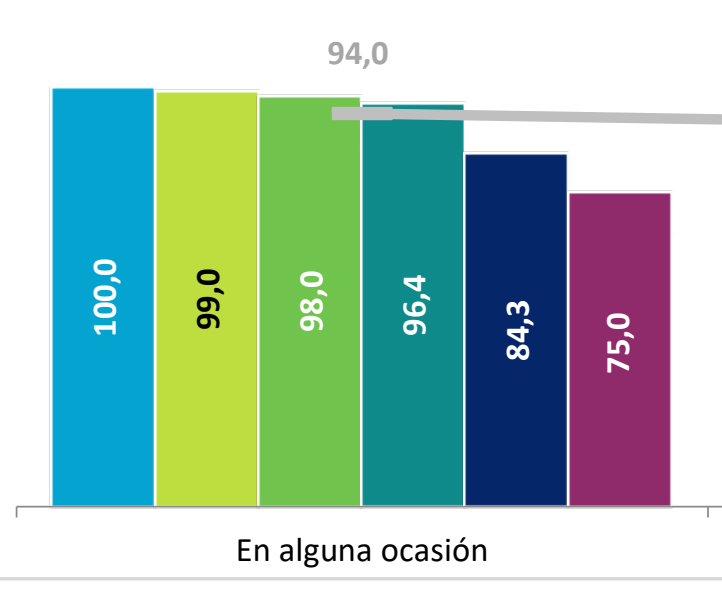

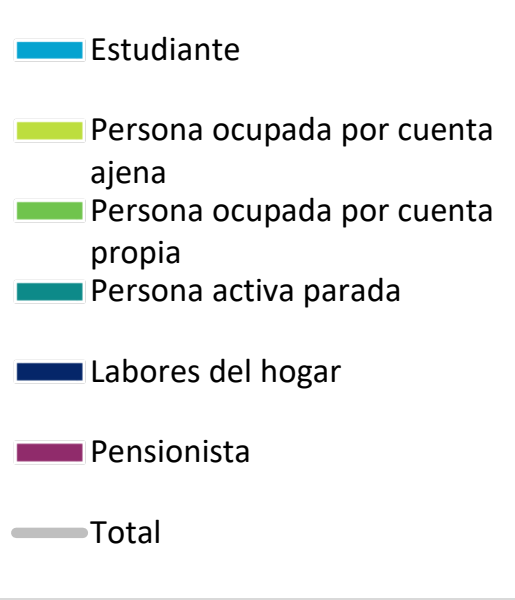

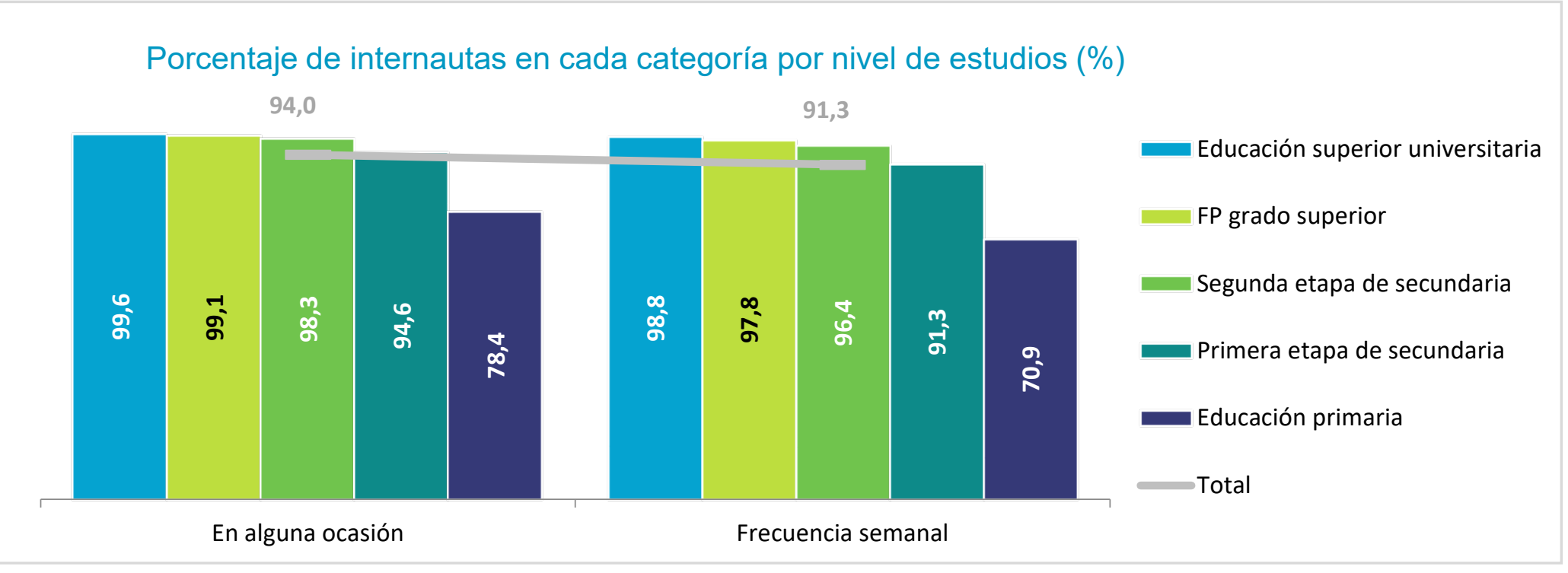


Un $81,1 \%$ de las personas residentes en hogares con rentas mensuales inferiores a los $900 €$ se conecta semanalmente, frente al $98,5 \%$ de los hogares con mayores rentas.

Estos porcentajes son ligeramente superiores si se consideran los internautas conectados ocasionalmente.
Porcentaje de internautas en cada categoría por renta neta por hogar (\%)

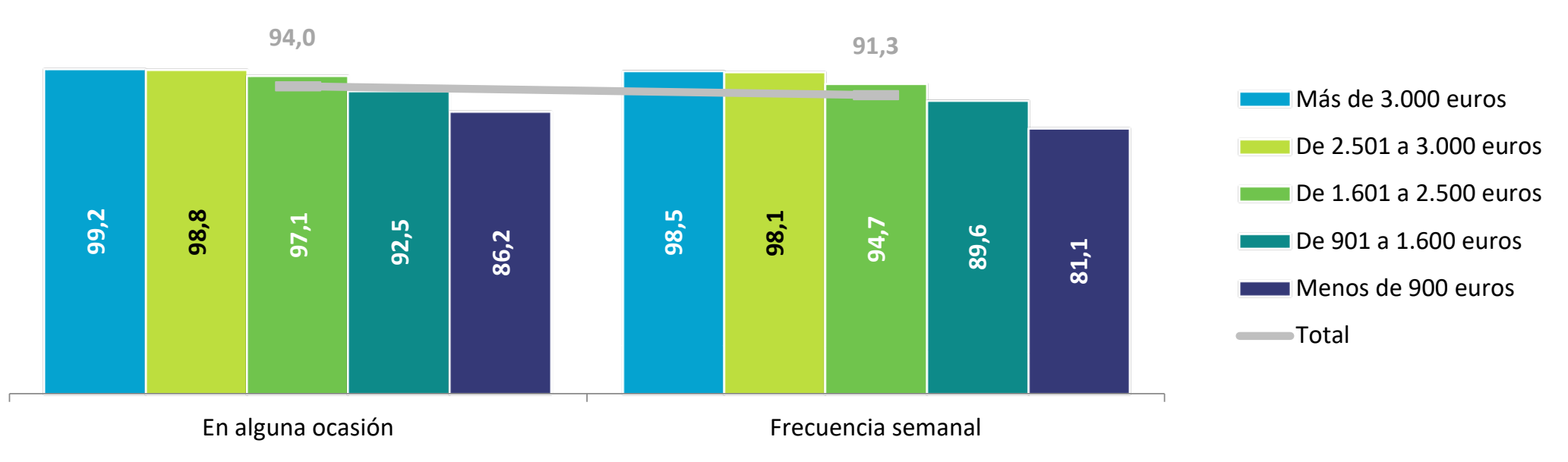

Porcentaje de internautas en cada categoría por tamaño de hábitat (\%)

El tamaño de hábitat no marca diferencias significativas en el uso de Internet.

Los porcentajes de internautas conectados ocasionalmente se sitúan entre el $90,7 \%$ en municipios pequeños de menos de 10 mil habitantes y el $96,7 \%$ de las grandes capitales de más de 500 mil habitantes.

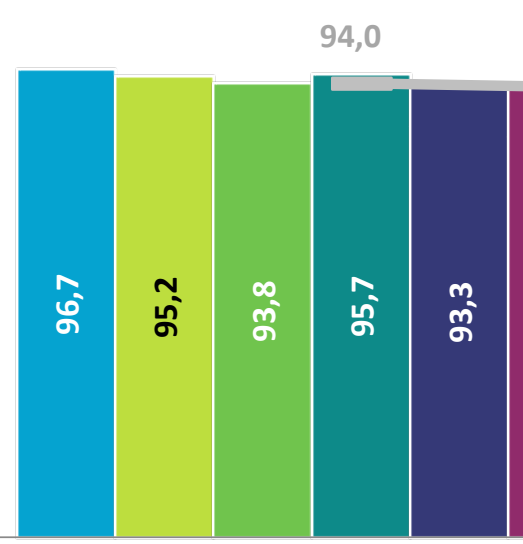

En alguna ocasión
91,3

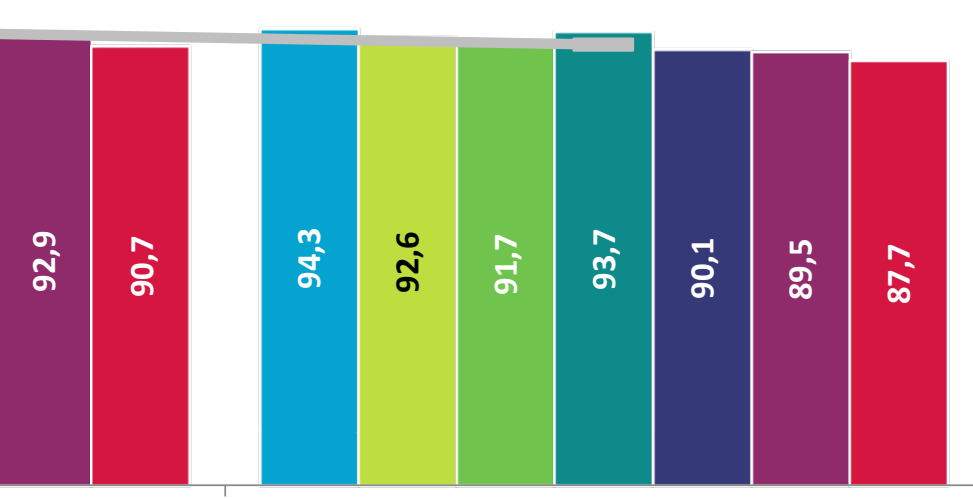

Frecuencia semanal
Capitales $>500$ mil hab. Capitales $<500$ mil hab. Municipio $>100$ mil hab. Municipio 50 a 100 mil hab. Municipio 20 a 50 mil hab. Municipio 10 a 20 mil hab Municipio < 10 mil hab. Total 
El $95,8 \%$ de los/as solteros/as accede a Internet semanalmente, siendo ligeramente inferior este porcentaje (92\%), si se consideran las personas divorciadas.

Los menores porcentajes de internautas se encuentran entre los/as viudos/as, el $76,5 \%$ se conectó a Internet en alguna ocasión y el $71,2 \%$ lo usa todas las semanas.

La presencia de hijos/as en el hogar influye positivamente en el uso de Internet. En los hogares de parejas con hijos/as, hay un $97,7 \%$ de internautas de alguna ocasión y un $96,2 \%$ de usuarios que se conectan semanalmente.

Por otro lado, estos porcentajes son del $87,3 \%$ y del $82,8 \%$ respectivamente en hogares de parejas $\sin$ hijos/as.
Porcentaje de internautas en cada categoría por estado civil (\%)
94,0

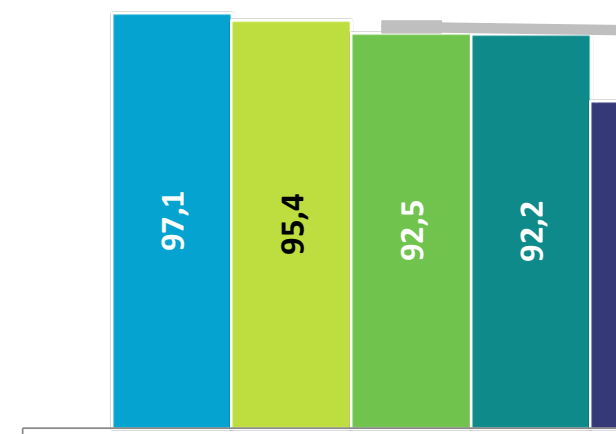

En alguna ocasión
91,3
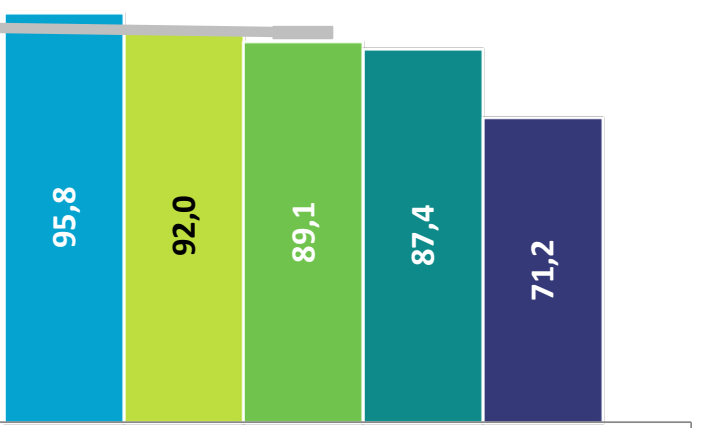

Frecuencia semanal
Soltero/a

Divorciado/a

Casado/a

Separado/a

Viudo/a

Total
Porcentaje de internautas en cada categoría por tipo de hogar (\%)

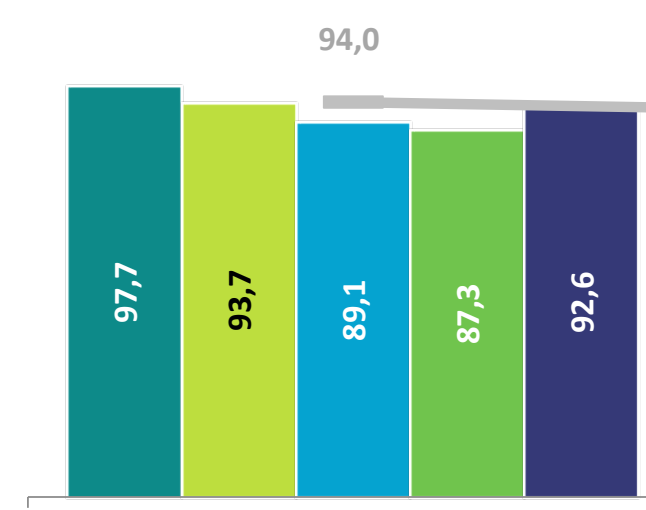

En alguna ocasión
91,3

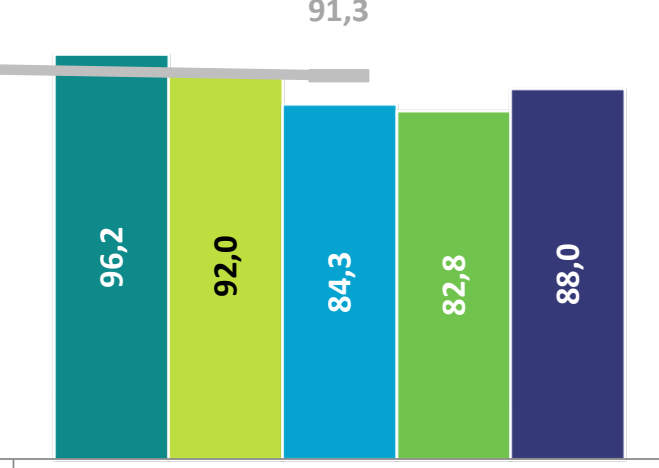

Frecuencia semanal
Pareja con hijos que conviva en el hogar

Padre o madre solo/a que conviva con algún hijo

Hogar unipersonal

Pareja sin hijos que conviva en el hogar

Otro tipo de hogar 
1. Número de internautas y frecuencia de uso

2. Uso de Internet por características sociodemográficas

3. Distribución sociodemográfica de la población internauta

4. Evolución del porcentaje de internautas

5. Protección de datos, seguridad en Internet e loT

6. Anexo y ficha técnica 
Los perfiles, tanto de la población que accedió a Internet en alguna ocasión como de los que se conectan todas las semanas, son iguales entre sí para hombres y mujeres, y también iguales al de la población total.

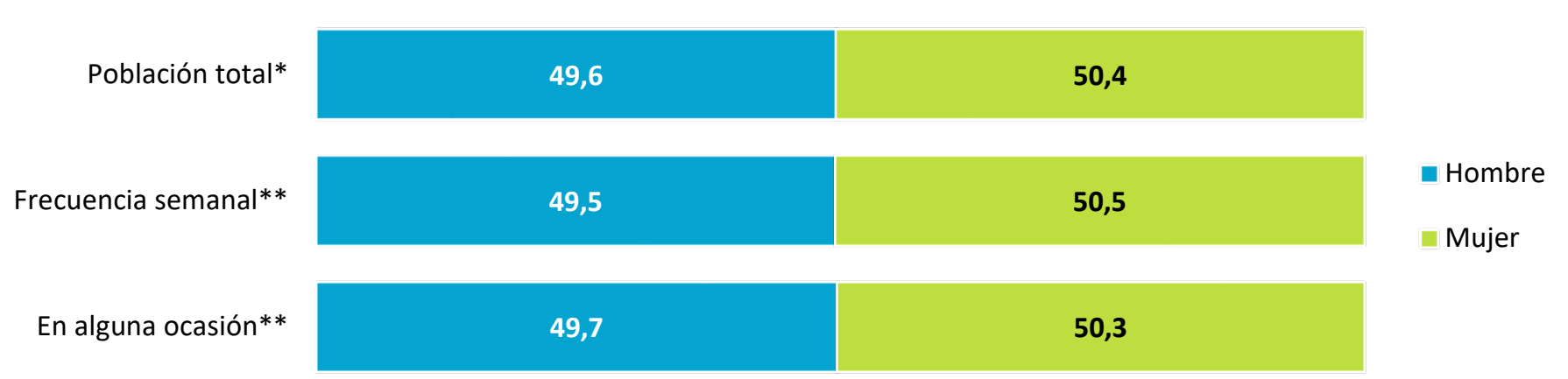

Distribución de internautas y población total por edad (\%)

La población internauta tiene un perfil ligeramente más joven que la población total, el $26,2 \%$ de los internautas semanales tiene 55 años o más frente al 31,2\% de la población total. La mayor diferencia se encuentra en el grupo de 65 a 74 años, el 9,3\% de los internautas de última semana pertenecen a esta franja de edad mientras que en la población representan más del 13\%.


18,0

13,2

- De 16 a 24 años

De 25 a 34 años

Frecuencia semanal**

13,4

22,4

16,9

9,3

En alguna ocasión**

13,0

21,9

\section{6,2}

22,4

\begin{tabular}{l|l}
15,8 & 21,5
\end{tabular}

22,2 
El $68,1 \%$ de las personas que acceden semanalmente a Internet están paradas u ocupadas, representando un porcentaje ligeramente inferior en la población total $(64,3 \%)$.

Sin embargo, el porcentaje de pensionistas es 3,6 puntos porcentuales mayor en la población total que en la población de internautas semanales.

$\begin{array}{lllr}\text { El } 27 \% \text { de los/as } & \text { internautas } \\ \text { semanales } & & \text { tienen } & \text { estudios }\end{array}$
universitarios, ligeramente por encima del de la población total, que se sitúa en el $25 \%$.

La población con estudios básicos (primaria o primaria incompleta) representa el $15 \%$ del total, 4,3 puntos porcentuales más que entre los usuarios semanales de Internet.

\section{Distribución de internautas y población total por situación laboral (\%)}
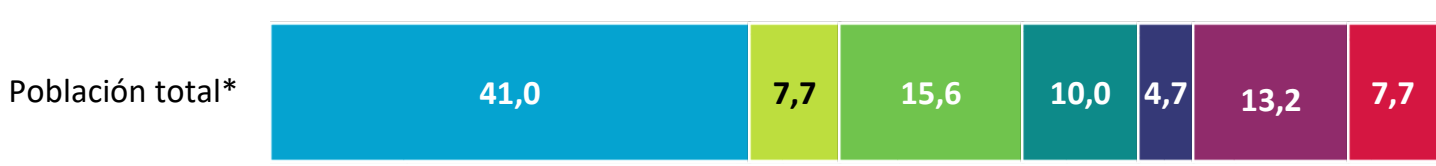

- Persona ocupada por cuenta ajena Persona ocupada por cuenta propia - Persona activa parada

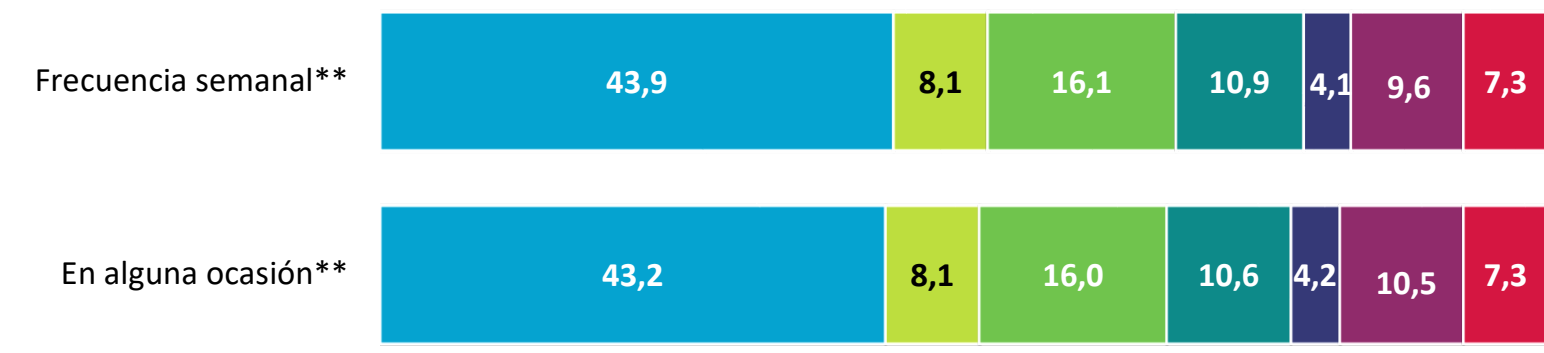

- Estudiante

- Labores del hogar

- Pensionista

- Otra situación laboral 
Los perfiles de internauta que se conecta en alguna ocasión y de acceso semanal en cuanto al nivel de renta del hogar son prácticamente idénticos.

Ambos tienen muy pequeñas diferencias respecto al de la población total, ligeramente menos personas en hogares con rentas inferiores a $900 €$ entre los internautas.
Distribución de internautas y población total por renta neta por hogar (\%)
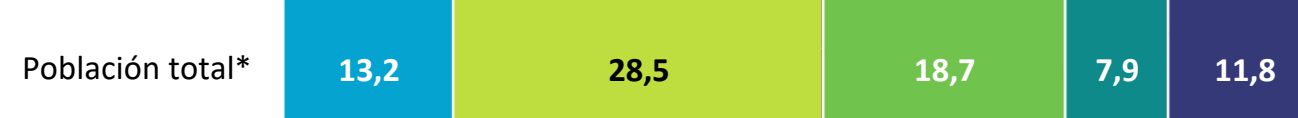

19,8

- Menos de 900 euros

De 901 a 1.600 euros

Frecuencia semanal**

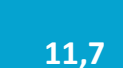

28,0

19,4

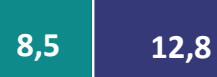

19,6

De 1.601 a 2.500 euros

- De 2.501 a 3.000 euros

• Más de 3.000 euros

En alguna ocasión**

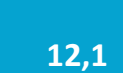

28,1

19,3



2,5

19,7

$\square \mathrm{Ns} / \mathrm{Nc}$

Distribución de internautas y población total por tamaño de hábitat (\%)

El tamaño de hábitat tampoco marca diferencias significativas entre los diferentes perfiles.

Se mantienen prácticamente las mismas proporciones de personas en los municipios de distintos tamaños entre los internautas y en la población total.
Población total*

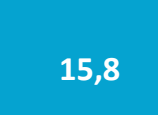

$$
15,9
$$

10,5
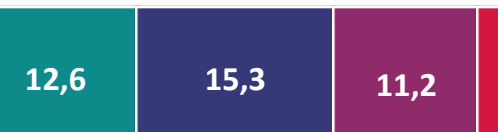

\section{6,3}

16,2

10,6

13,0

11,0

17,9
16,1

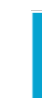

\section{5,1}

11,0

En alguna ocasión**

\section{6,3}

12,9
15,1

11,1

18,0 $\square$ Capitales $>500$ mil hab.

$\square$ Capitales $<500$ mil hab.

$\square$ Municipio > 100 mil hab.

- Municipio 50 a 100 mil hab.

- Municipio 20 a 50 mil hab.

- Municipio 10 a 20 mil hab

- Municipio < 10 mil hab. 
El $40 \%$ de los internautas que acceden semanalmente son solteros/as y el $51,3 \%$ están casados/as.

Estos porcentajes son muy similares con los que acceden en alguna ocasión y con la distribución que muestra la población total.

Por tipología de hogar, se observan algunas diferencias, casi el $51 \%$ de los/as internautas que acceden semanalmente forman un hogar con pareja e hijos/as, ligeramente superior al perfil de la población total, que alcanza el 48,2\%. Se observa también menor proporción de hogares formados por pareja sin hijos entre los internautas.
Población total*

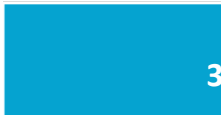

38,1

52,6

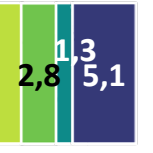

- Soltero/a

Casado/a

Frecuencia semanal**
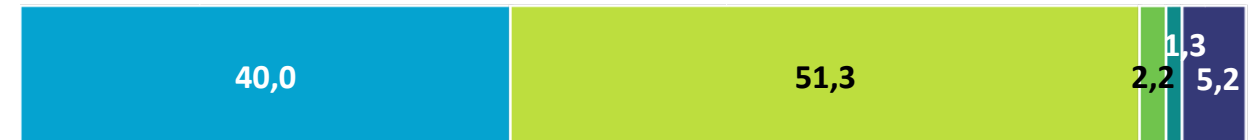

- Viudo/a

- Separado/a

En alguna ocasión**

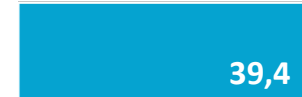

51,8



- Divorciado/a

Distribución de internautas y población total por tipo de hogar (\%)

Población total*



\section{8,2}

50,8

Frecuencia semanal**

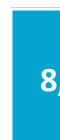

13,7

15,6

En alguna ocasión**

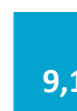

3,5

16,0

50,1
- Hogar unipersonal

- Padre o madre solo/a que conviva con algún hijo

- Pareja sin hijos que conviva en el hogar

- Pareja con hijos que conviva en el hogar

- Otro tipo de hogar 
1. Número de internautas y frecuencia de uso

2. Uso de Internet por características sociodemográficas

3. Distribución sociodemográfica de la población internauta

4. Evolución del porcentaje de internautas

5. Protección de datos, seguridad en Internet e loT

6. Anexo y ficha técnica 
En el último año, el porcentaje de internautas que se conectan semanalmente a Internet alcanza el 94\%, tras un incremento de 3,6 puntos porcentuales durante el último año. Destaca el aumento interanual de 5,5 puntos porcentuales en el porcentaje de personas que acceden diariamente a Internet, situándose a finales de 2020, en el 83,1\% de la población.

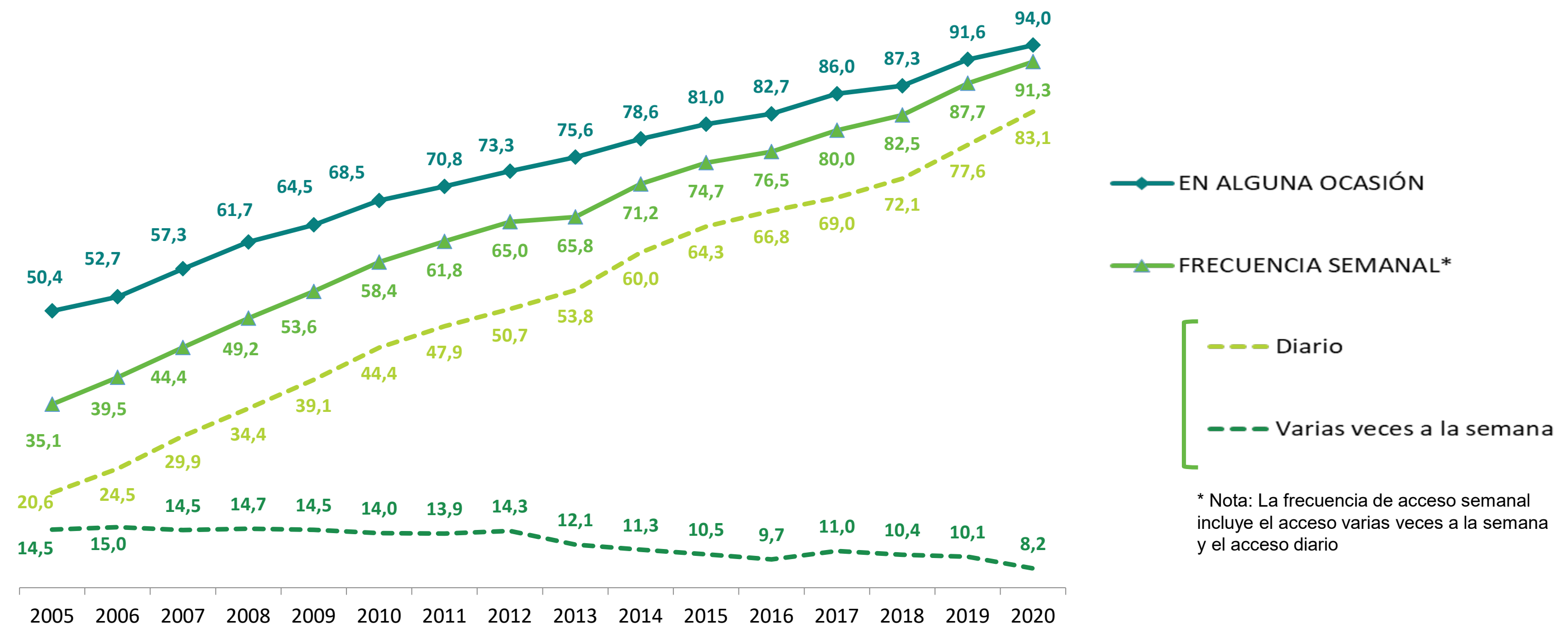


Durante 2020 continúan avanzando en la utilización de Internet los perfiles con menor uso, destacando especialmente las personas dedicadas a las labores del hogar y con estudios primarios, con incrementos superiores a los 8 puntos. En el caso de los colectivos de viudos/as y personas de 65 a 74 años, el incremento es superior a 6 puntos porcentuales en ambos casos.

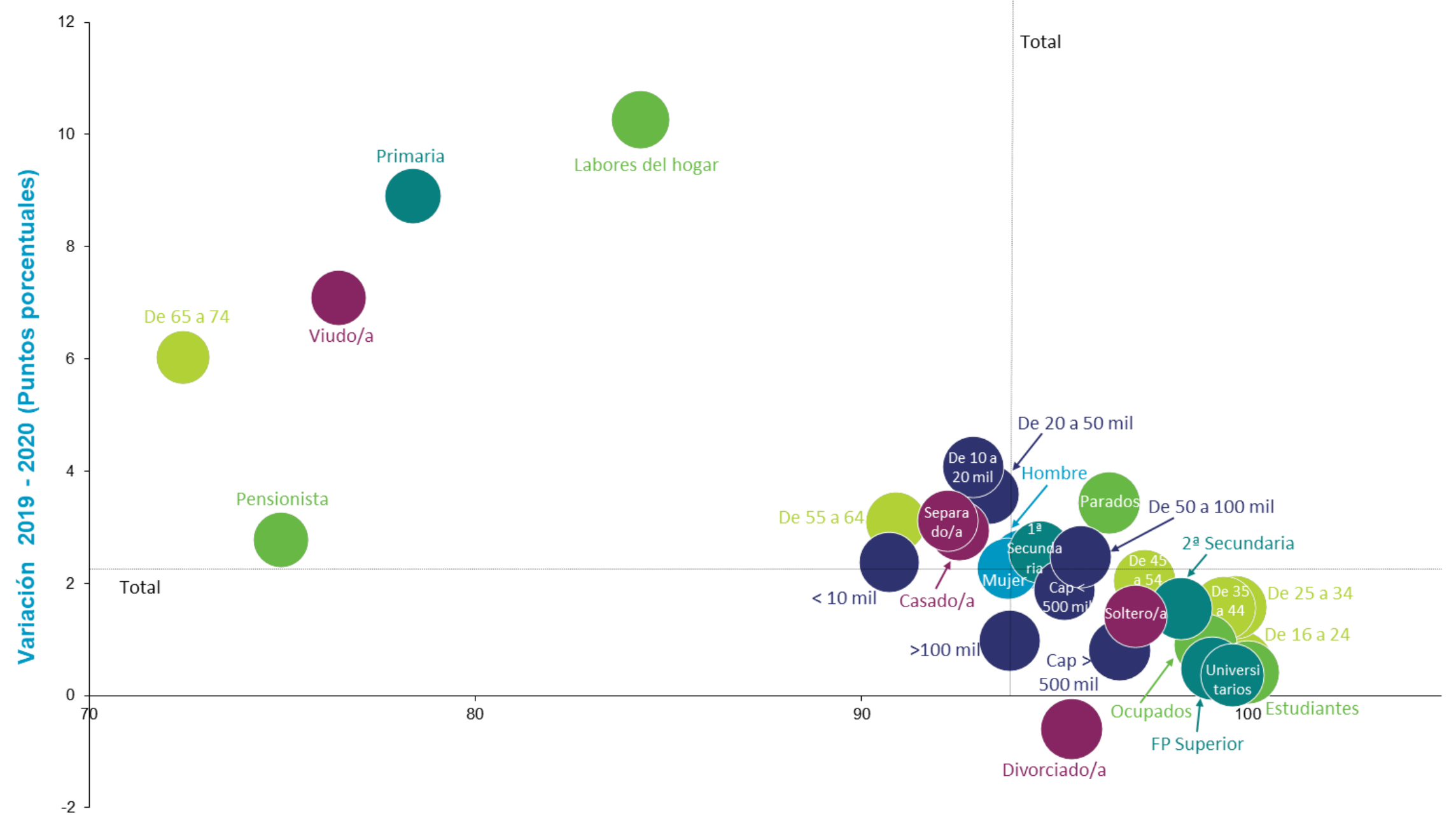

Género

Edad

Situación laboral

Estudios terminados

Hábitat

Estado civil

Porcentaje de Internautas 2020 (\%) 
El acceso semanal a Internet se incrementó de manera notable entre las personas dedicadas a las tareas del hogar, registrando un aumento interanual de 10 puntos porcentuales. También son notables los crecimientos de aquellos/as con estudios primarios y las personas viudas respecto al año anterior, en estos casos, rondan los 9 puntos porcentuales.

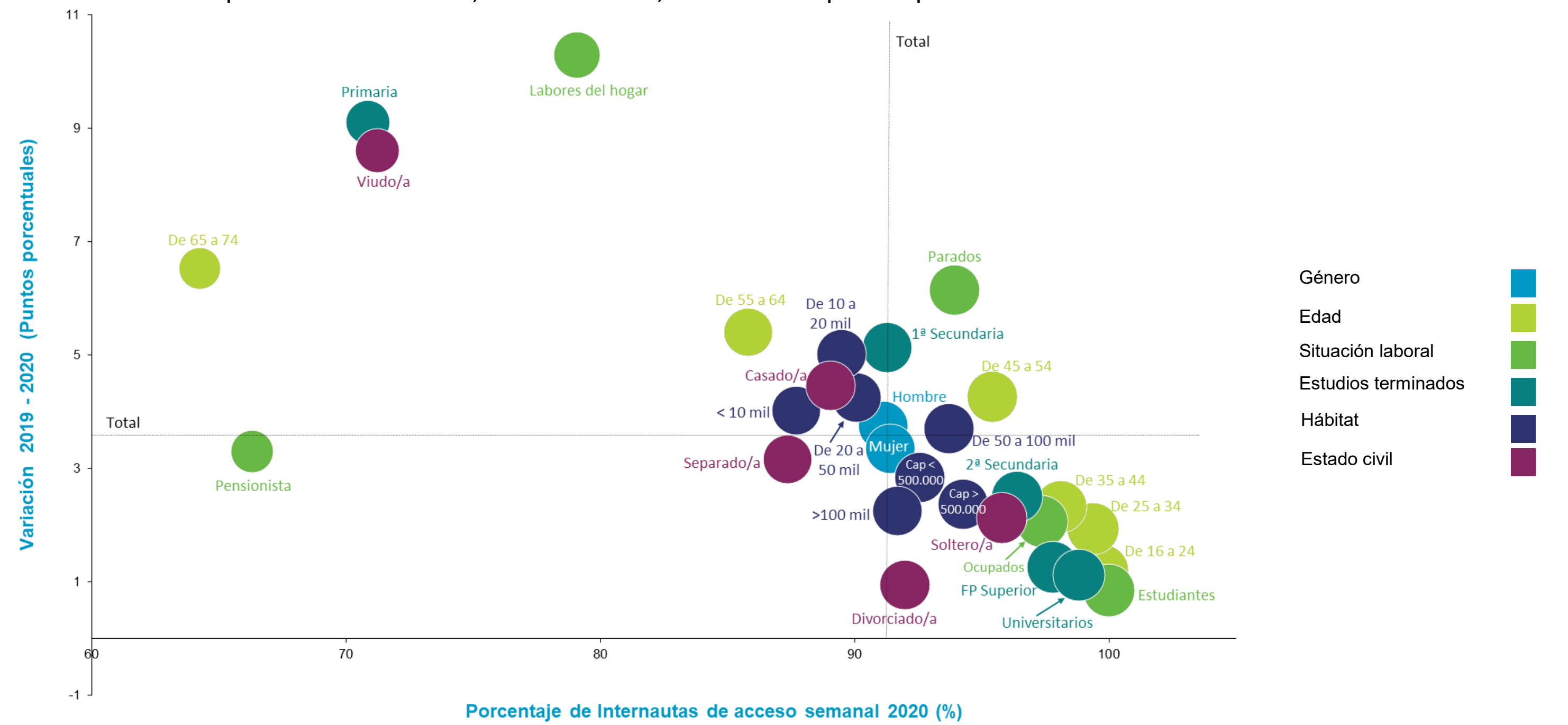


1. Número de internautas y frecuencia de uso

2. Uso de Internet por características sociodemográficas

3. Distribución sociodemográfica de la población internauta

4. Evolución del porcentaje de internautas

5. Protección de datos, seguridad en Internet e loT

6. Anexo y ficha técnica 


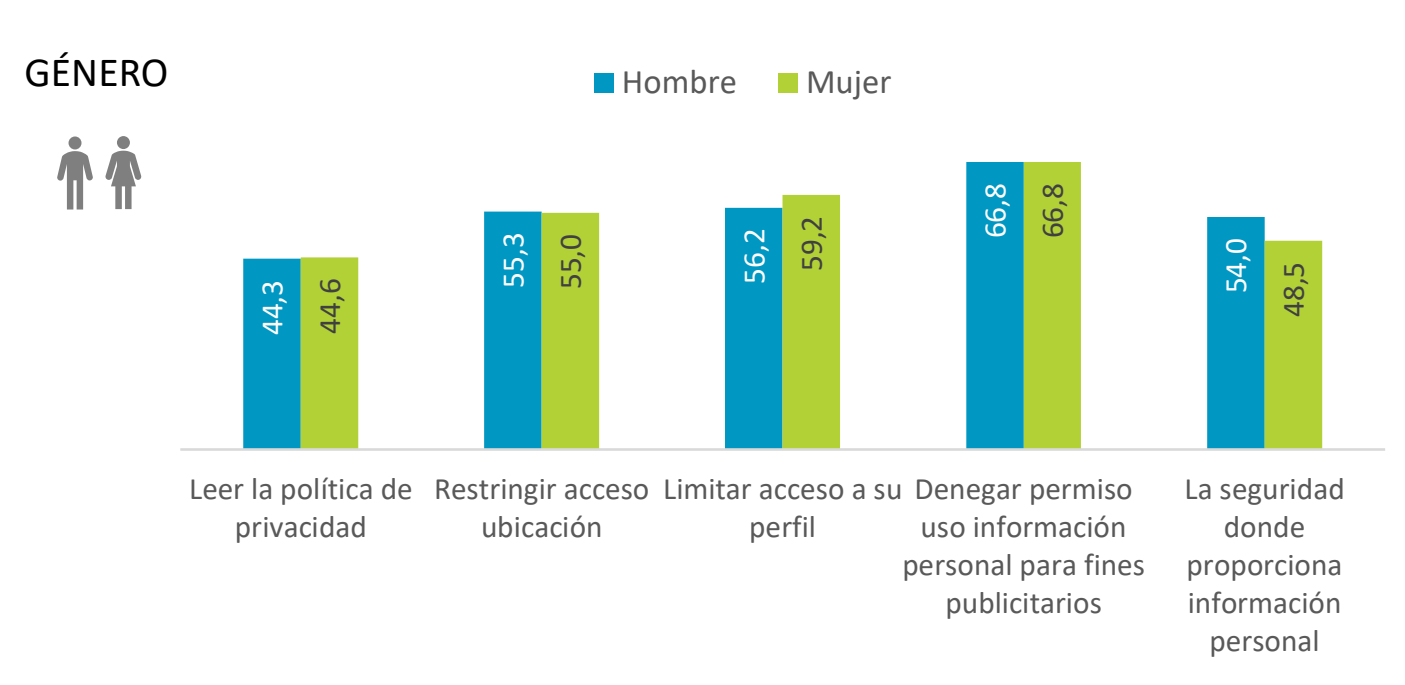

A la hora de realizar alguna acción para gestionar el acceso de la información personal en Internet, las mujeres limitan en mayor medida que los hombres, el acceso a su perfil o contenido en las redes sociales 0 de almacenamiento compartido.

Sin embargo, los hombres realizan mayores comprobaciones de seguridad que las mujeres en los sitios web donde se necesita proporcionar información personal, como por ejemplo, comprobar si existía un logotipo o certificado o la existencia de una " $s$ " tras el "http".

\section{EDAD}

• De 16 a 24 años De 25 a 34 años De 35 a 44 años

낸?

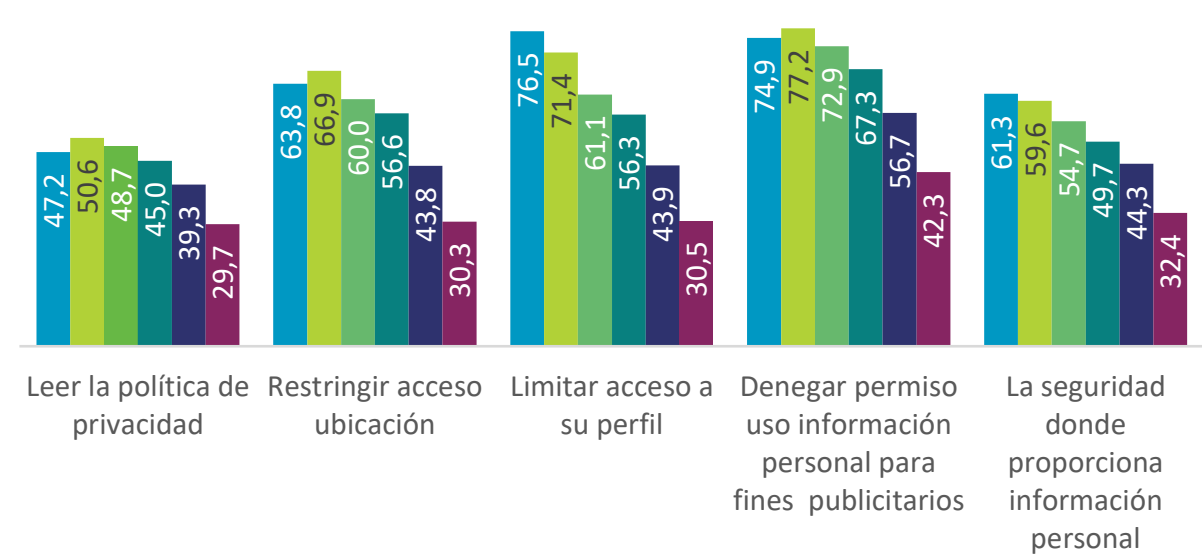

De manera general, los perfiles más jóvenes son los que realizan más medidas de control para gestionar su información personal en el uso de la Red. Destaca el grupo menor edad a la hora de limitar su perfil en las redes sociales, así como a la hora de realizar comprobaciones en el momento de navegar por Internet.

Otras acciones como leer la política de privacidad, restringir el acceso a la ubicación geográfica o denegar permisos de información personal con fines publicitarios, presentan en las personas de 25 a 34 años sus máximos valores. 
El nivel educativo marca diferencias en las prácticas llevadas a cabo por la ciudadanía en cuanto a la privacidad y protección de datos personales.

A mayor nivel educativo, mayor nivel de prevención en el uso de Internet, así se observa en los más de 25 puntos porcentuales de diferencia entre la población con nivel educativo alto y nivel educativo bajo, a la hora de realizar acciones como restringir el acceso a la ubicación geográfica, limitar accesos al utilizar redes sociales, o denegar permisos de información personal con fines publicitarios.
- Bajo nivel educativo $\square$ Medio nivel educativo $\square$ Alto nivel educativo

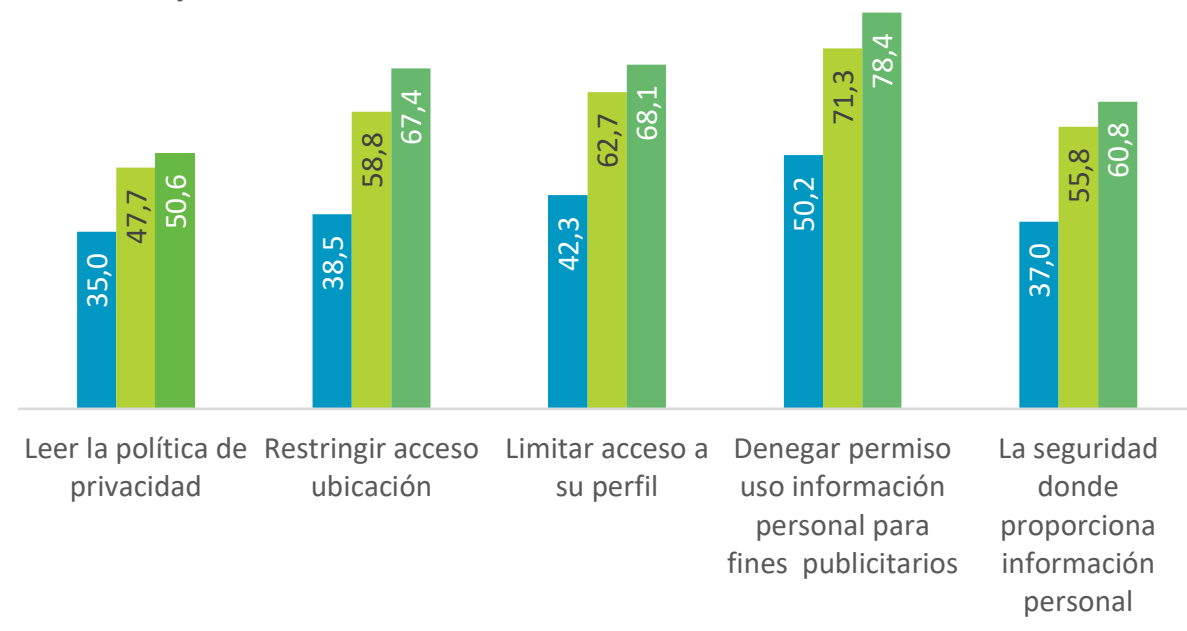

NIVEL DE ESTUDIOS

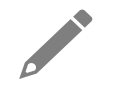

Referente a la situación laboral, se observa un patrón de comportamiento más comprometido con la seguridad entre los estudiantes y la población ocupada.

No obstante, es la población desempleada la que muestra un mayor nivel de responsabilidad a la hora de leer la política de privacidad.

Los grupos de población que menos utilizan las opciones disponibles en cuanto privacidad y protección de datos personales, son los pensionistas y otra población inactiva.

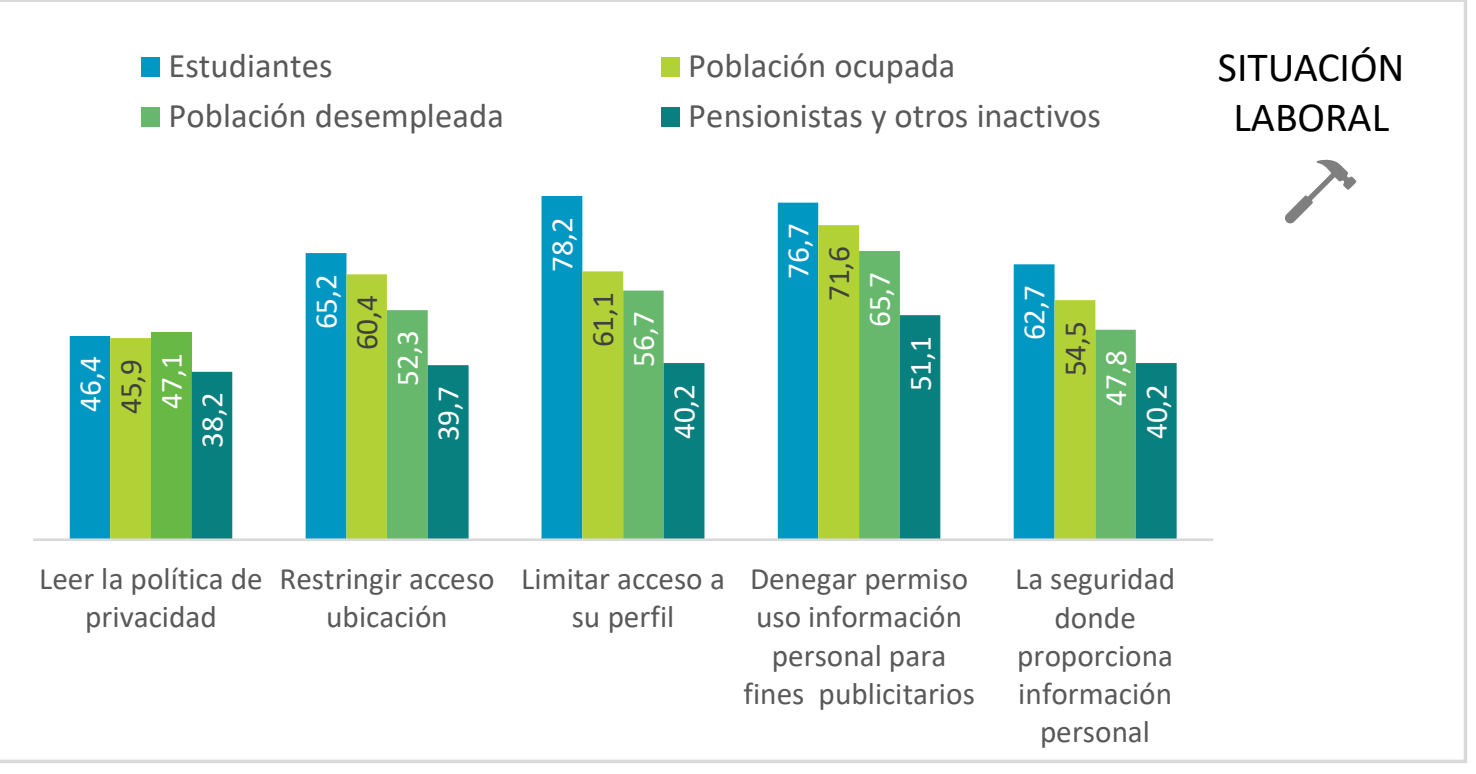




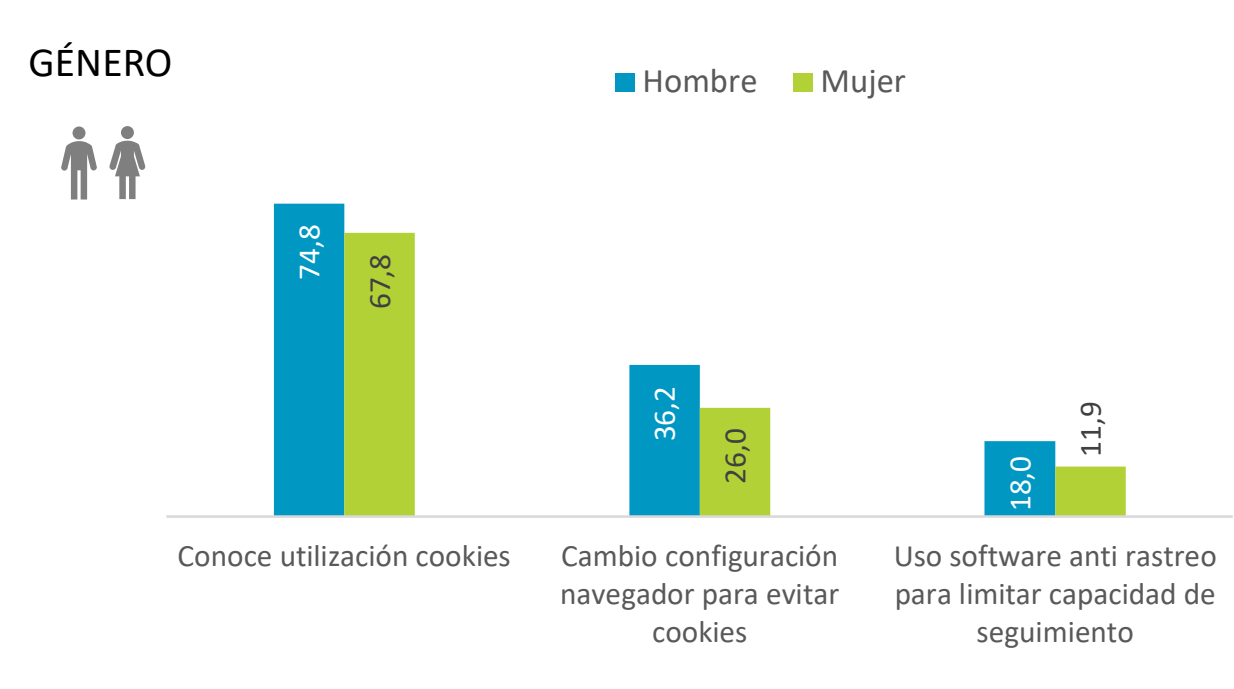

EDAD

• De 16 a 24 años — De 25 a 34 años — De 35 a 44 años

- De 45 a 54 años De 55 a 64 años De 65 a 74 años

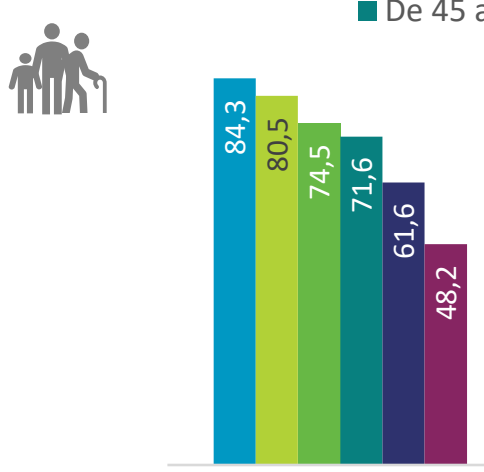

Conoce utilización cookies

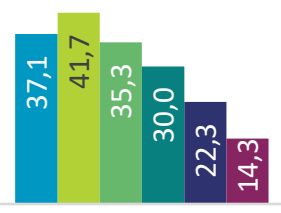

Cambio configuración navegador para evitar cookies

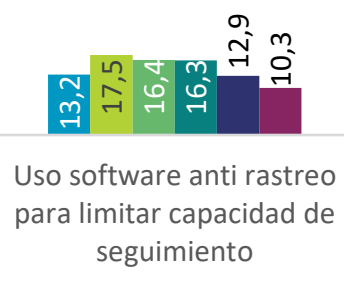

Se aprecia un comportamiento diferente entre hombres $y$ mujeres en el conocimiento de qué son y para qué se utilizan las cookies. El $74,8 \%$ de los hombres sabe que se utilizan para rastrear los movimientos de personas en Internet, realizar un perfil del usuario y presentarle anuncios a medida, mientras que en el caso de las mujeres este porcentaje desciende al $67,8 \%$.

Asimismo los hombres $(36,2 \%)$ superan a las mujeres $(26 \%)$ en la modificación de la configuración de su navegador de Internet, para prevenir o limitar la cantidad de cookies.

A menor edad, mayor conocimiento de lo qué es y para qué se utilizan las cookies. Se recoge una diferencia de 36 puntos porcentuales entre la población de menor edad, de 16 a 24 años y la de mayor edad, de 65 a 74 años.

No obstante, es el grupo de edad de 25 a 34 años el que se muestra más proactivo a la hora de limitar la cantidad cookies; cuatro de cada diez personas de ese rango de edad, realizan alguna modificación en la configuración de su propio navegador de Internet con ese fin. 
El nivel educativo también muestra diferencias en lo relativo al conocimiento de la funcionalidad de las cookies; el $85,8 \%$ de la población con un nivel educativo alto, declara saber que las cookies rastrean los movimientos de las personas cuando navegan por la Red, por ejemplo, para dirigirle publicidad, mientras que ese mismo porcentaje se sitúa en el $52,7 \%$ en el caso del grupo de población con nivel educativo bajo.

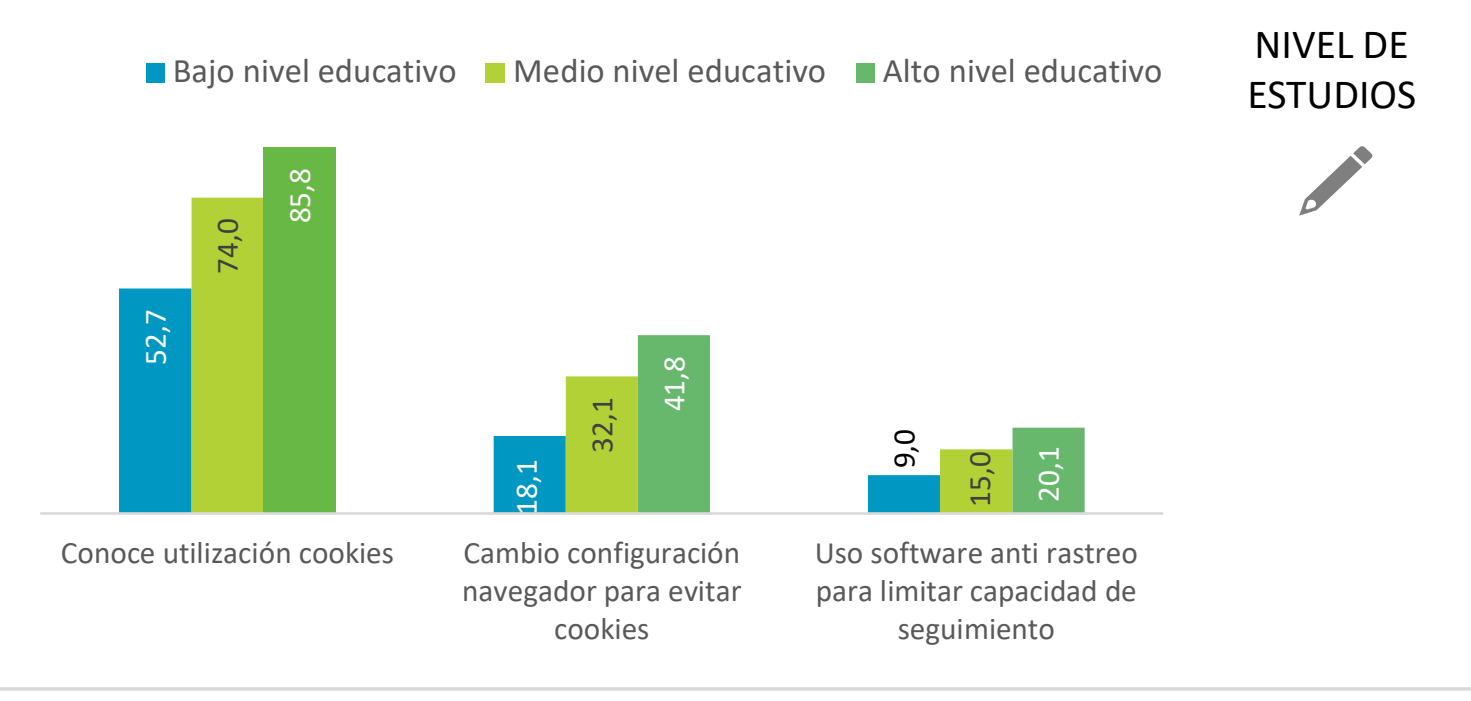

Los estudiantes son los que más conocen la funcionalidad y las posibilidad que ofrece la utilización de las cookies: el 87,4\% de ellos saben como funcionan y el $40,8 \%$ realizan cambios en la configuración de su navegador para evitarlas. En este indicador, se aprecia una diferencia de 31,8 puntos porcentuales, respecto a pensionistas y población desempleada.

Sin embargo, el grupo de población ocupada es el que más utiliza algún tipo de software anti-rastreo para limitar la capacidad de seguimiento de sus actividades en Internet en cualquiera de sus dispositivos.

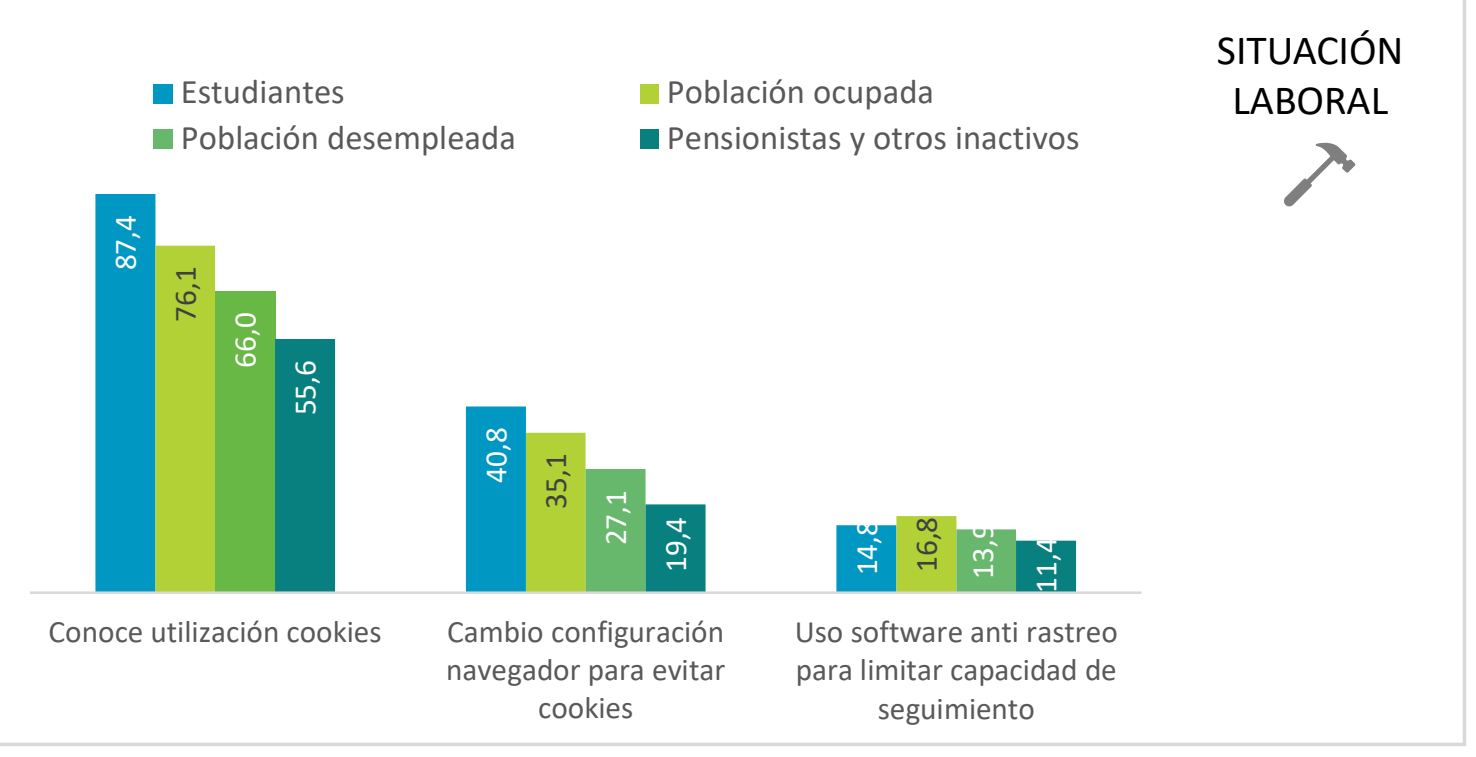


El 59,3\% de la población española declara tener mucha o bastante confianza en Internet. Segmentado por las variables sociodemográficas de género, edad, situación laboral y nivel de estudios, se observa que son los hombres (61,5\%), las personas de 16 a 24 años (64,7\%), los estudiantes $(67,9 \%)$ y las personas de nivel educativo alto (64,9\%), quienes presentan valores por encima de la media

\begin{tabular}{|c|c|c|}
\hline POCA O NADA & BASTANTE O MUCHA \\
\hline 40,7 & 59,3 \\
\hline
\end{tabular}
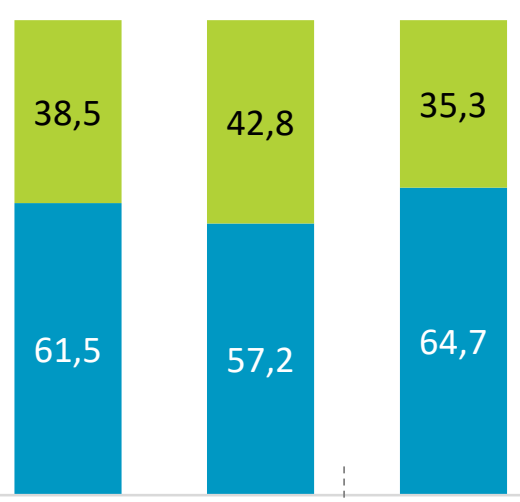

을
음

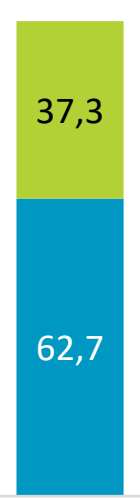

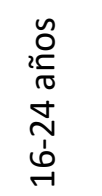

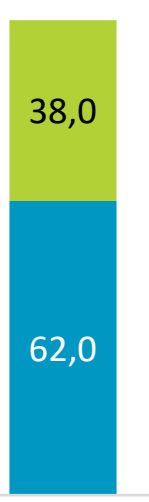

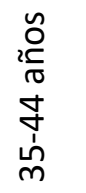

EDAD
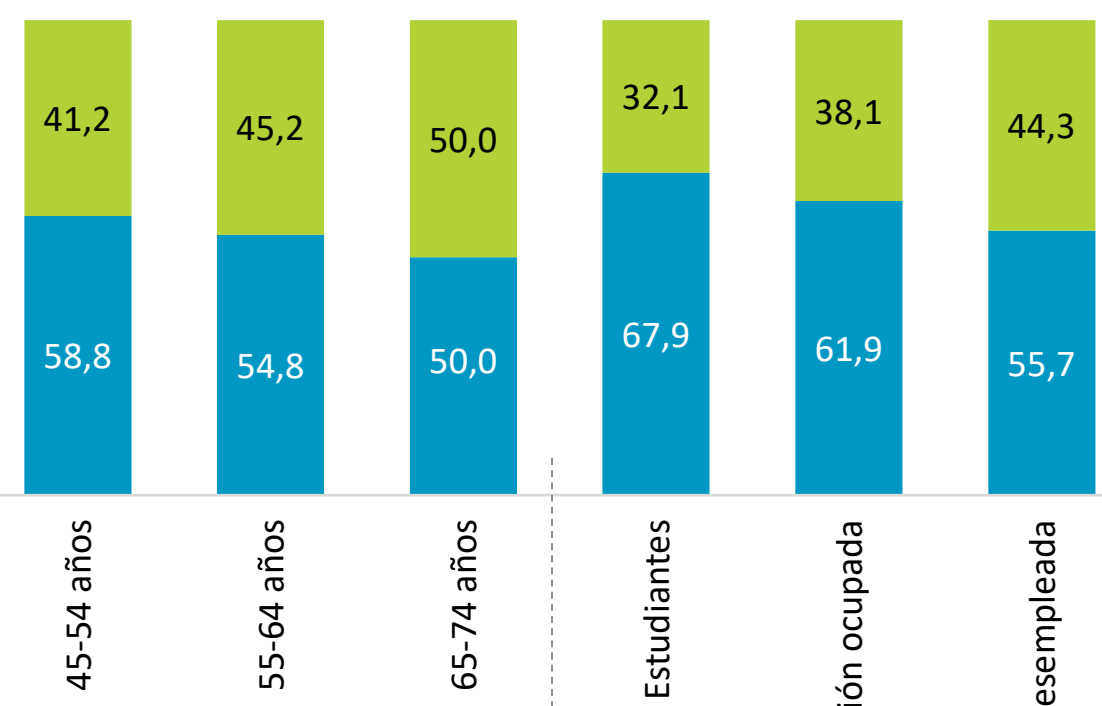

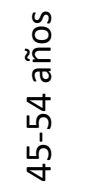



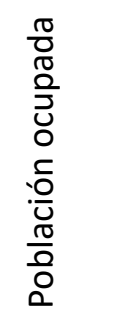

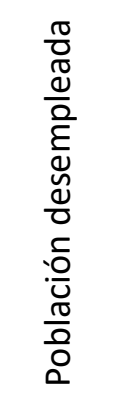

SITUACIÓN LABORAL

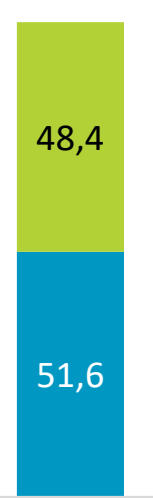

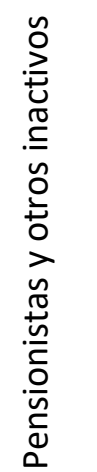

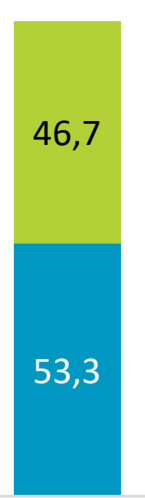

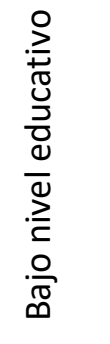

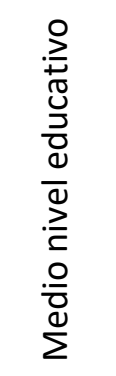

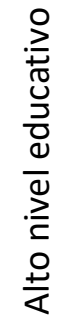

NIVEL DE ESTUDIOS 
El $88 \%$ de los/as internautas utiliza algún tipo de procedimiento de identificación para poder utilizar servicios online; el $83,7 \%$ inicia sesión con un usuario y contraseña, el $65,2 \%$ recibe mensajes con código en su teléfono móvil y el $45,7 \%$ de los/as internautas inician sesión en una red social para poder acceder a otros servicios. En este último caso, destaca que este procedimiento es utilizado por el $70 \%$ de los/as estudiantes y el $65,4 \%$ de las personas de 25 a 34 años
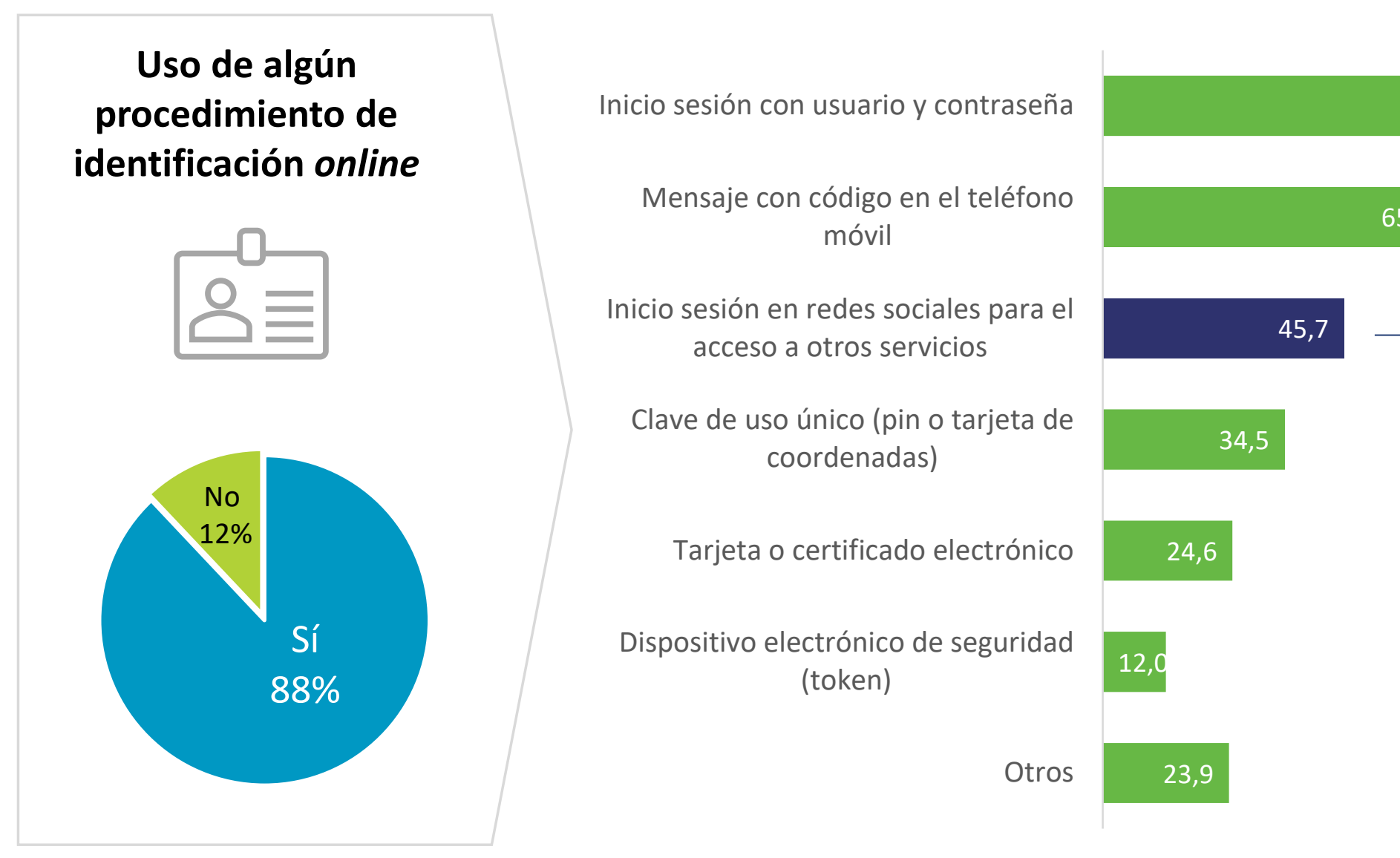
El 79,5\% de los internautas dispone de algún dispositivo conectado a Internet. Entre las mujeres la no disponibilidad de dispositivos conectados tiene mayor presencia, al igual que sucede según aumenta la edad y conforme desciende el nivel educativo. Por el contrario, entre los hombres estos dispositivos muestran mayor penetración, al igual que entre las edades más jóvenes, los estudiantes y en relación al aumento del nivel educativo.
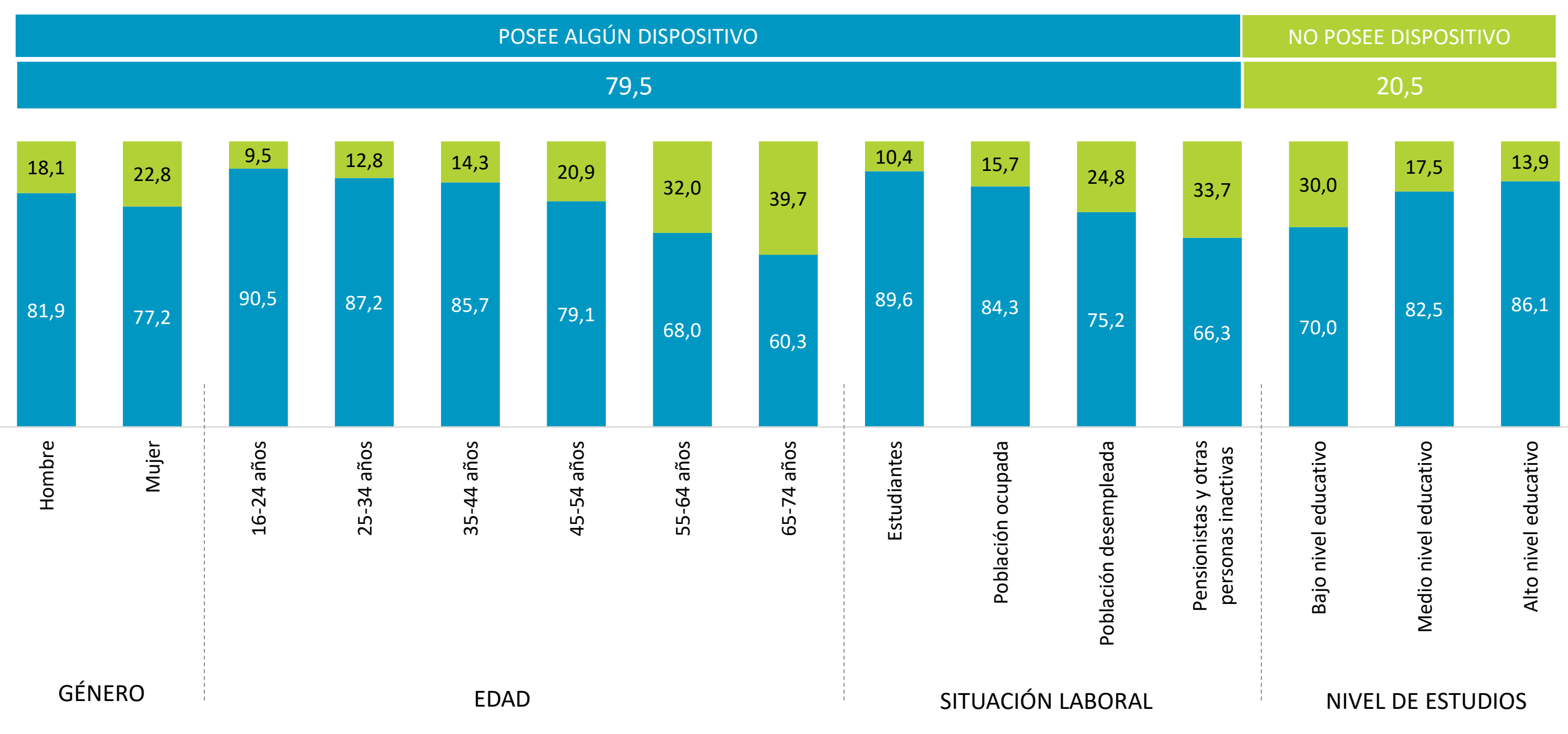

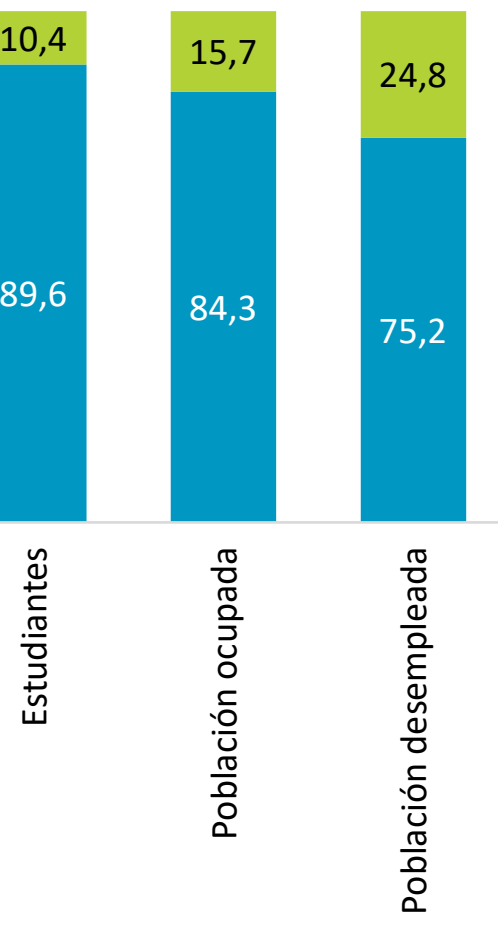

SITUACIÓN LABORAL

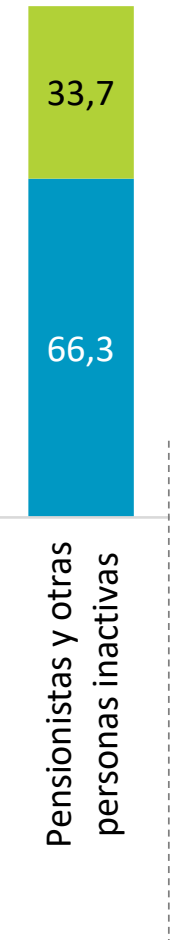

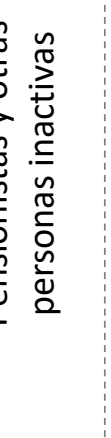

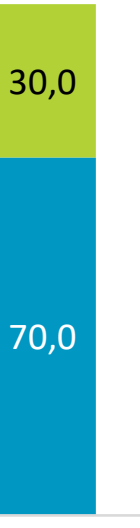

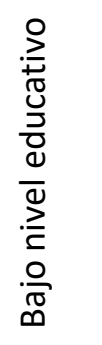

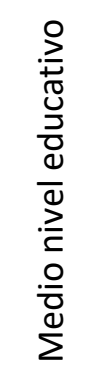

NIVEL DE ESTUDIOS 
El televisor conectado es el principal dispositivo con conexión que los internautas han utilizado $(71,2 \%)$. Entre los dispositivos individuales el reloj inteligente y los auriculares conectados son los dispositivos más extendidos (24,3\%). El 31,1\% utilizó algún dispositivo de domótica, siendo la principal razón para no utilizarlo la percepción de falta de necesidad.

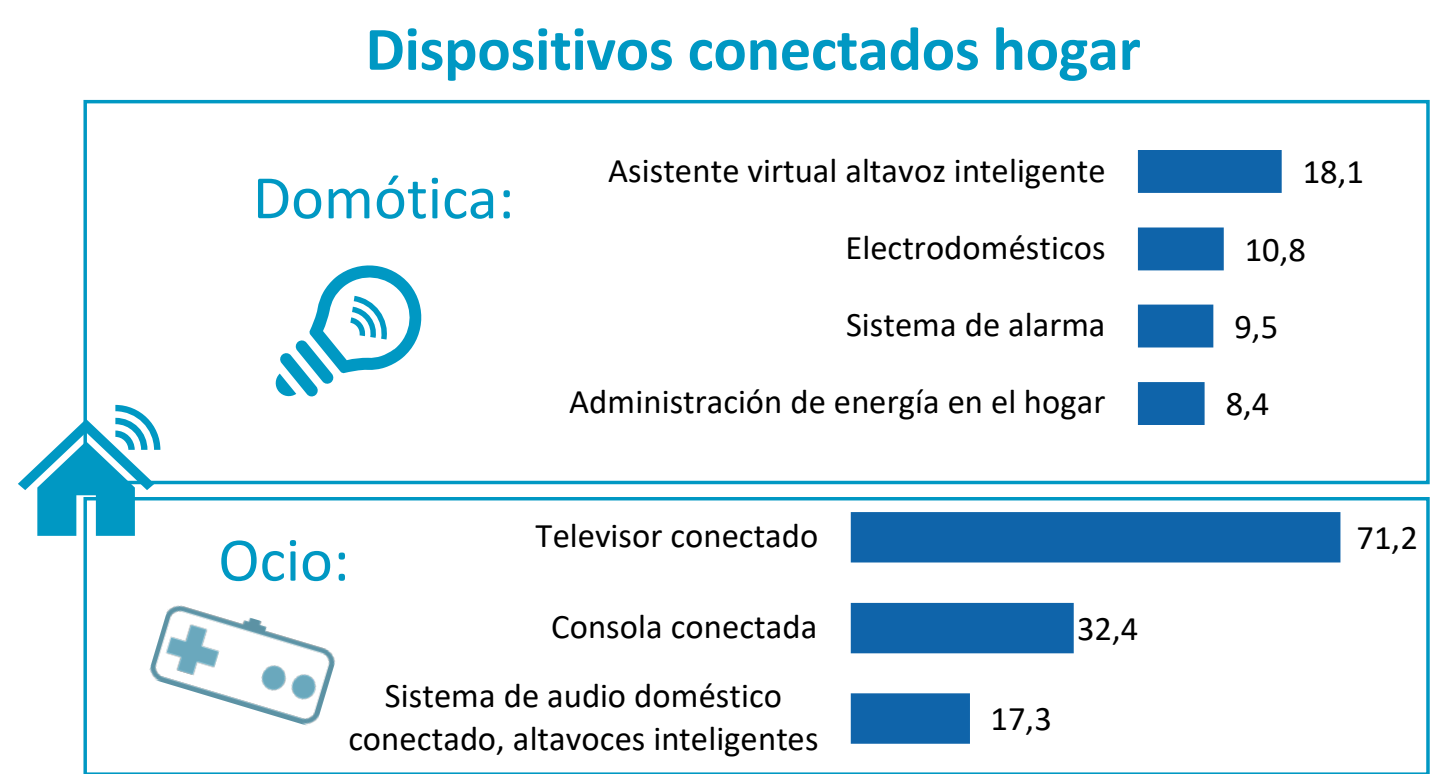

\section{Dispositivos conectados Individuales}

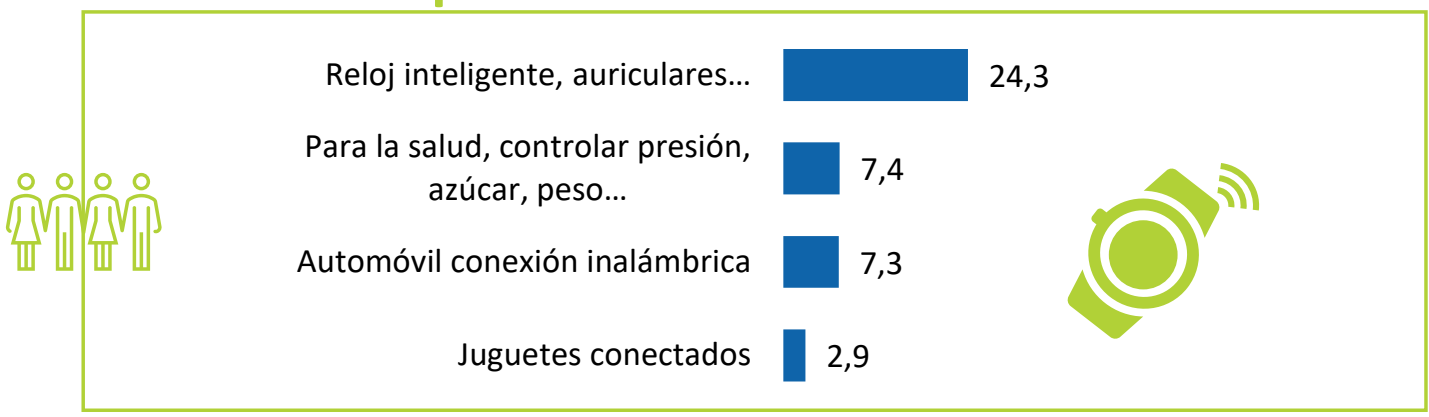

Dispositivos domóticos

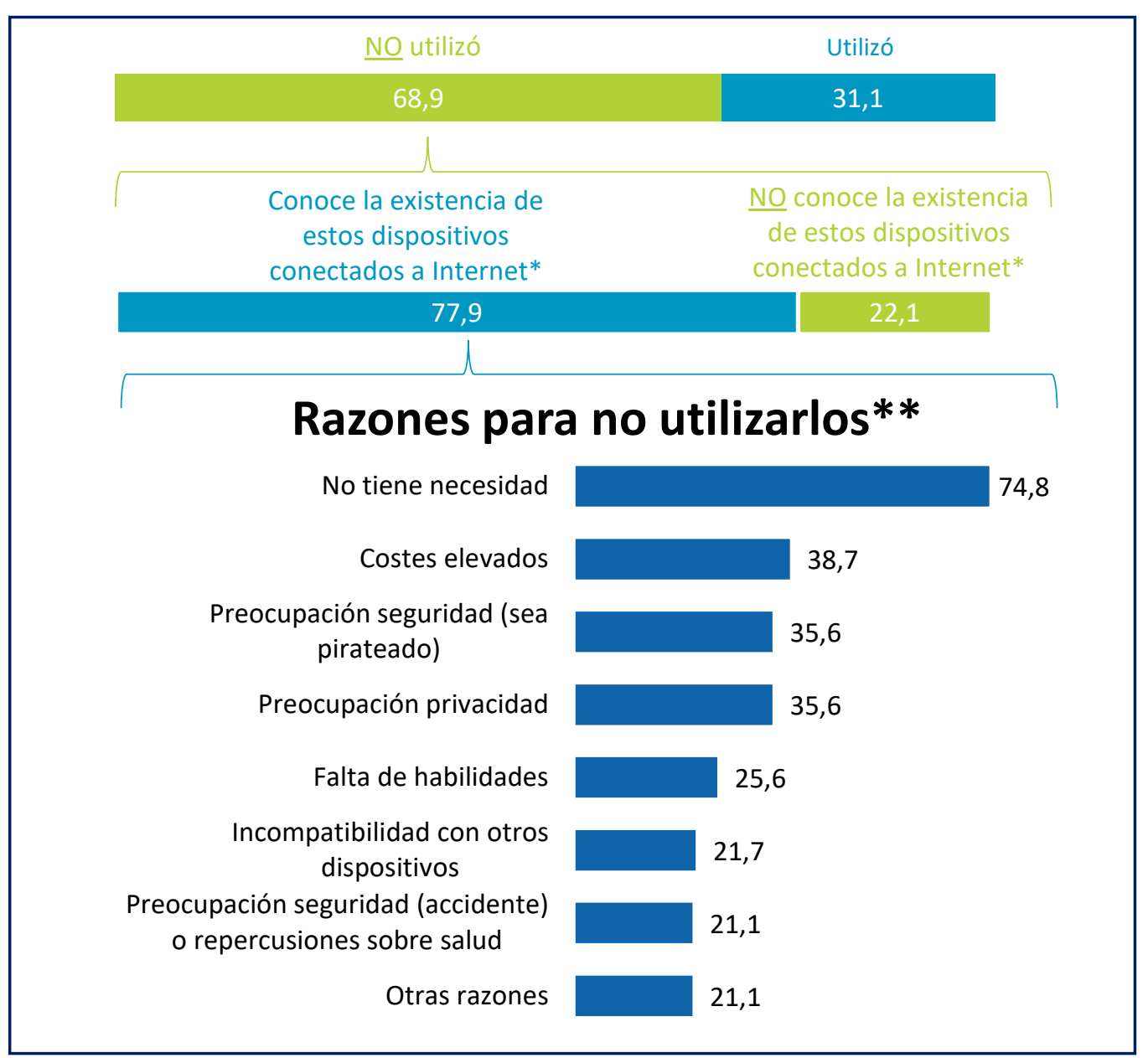

Base: población Internauta en los últimos 3 meses de 16 a 74 años Base*: Población Internauta en los últimos 3 meses de 16 a 74 años que no utilizó dispositivos de domótica Base $^{* *}$ : población Internauta en los últimos 3 meses de 16 a 74 años que no utiliza dispositivos de domótica, aunque conoce la existencia de dispositivos conectados a Internet 
1. Número de internautas y frecuencia de uso

2. Uso de Internet por características sociodemográficas

3. Distribución sociodemográfica de la población internauta

4. Evolución del porcentaje de internautas

5. Protección de datos, seguridad en Internet e loT

\section{Anexo y ficha técnica}




\begin{tabular}{|c|c|c|c|c|c|c|c|}
\hline & \multirow[b]{2}{*}{$\%$ de individuos } & \multicolumn{3}{|c|}{ Internautas (\%) } & \multicolumn{3}{|c|}{ Internautas acceso semanal (\%) } \\
\hline \multirow{3}{*}{ Género } & & 2018 & 2019 & 2020 & 2018 & 2019 & 2020 \\
\hline & Hombre & 87,8 & 91,7 & 94,2 & 83,0 & 87,4 & 91,1 \\
\hline & Mujer & 86,8 & 91,5 & 93,8 & 82,0 & 88,0 & 91,4 \\
\hline \multirow{6}{*}{ Edad } & De 16 a 24 años & 98,5 & 99,2 & 99,8 & 96,9 & 98,5 & 99,8 \\
\hline & De 25 a 34 años & 98,0 & 98,1 & 99,7 & 96,1 & 97,5 & 99,4 \\
\hline & De 35 a 44 años & 97,1 & 97,8 & 99,4 & 95,0 & 95,8 & 98,1 \\
\hline & De 45 a 54 años & 91,5 & 95,3 & 97,3 & 87,0 & 91,1 & 95,4 \\
\hline & De 55 a 64 años & 78,3 & 87,8 & 90,9 & 69,6 & 80,4 & 85,8 \\
\hline & De 65 a 74 años & 52,9 & 66,4 & 72,4 & 42,5 & 57,7 & 64,3 \\
\hline \multirow{7}{*}{$\begin{array}{c}\text { Situación } \\
\text { Laboral }\end{array}$} & Población ocupada por cuenta ajena & 96,1 & 98,0 & 99,0 & 93,6 & 95,5 & 97,7 \\
\hline & Población ocupada por cuenta propia & 92,3 & 97,1 & 98,0 & 88,2 & 93,7 & 95,6 \\
\hline & Población activa parada & 90,5 & 93,0 & 96,4 & 84,2 & 87,8 & 93,9 \\
\hline & Estudiante & 99,5 & 99,6 & 100,0 & 98,2 & 99,2 & 100,0 \\
\hline & Labores del hogar & 62,2 & 74,0 & 84,3 & 53,8 & 68,8 & 79,1 \\
\hline & Pensionista & 59,8 & 72,2 & 75,0 & 49,0 & 63,0 & 66,3 \\
\hline & Otra situación laboral & 73,5 & 78,4 & 88,7 & 65,7 & 71,7 & 86,1 \\
\hline \multirow{6}{*}{$\begin{array}{l}\text { Estudios } \\
\text { Terminados }\end{array}$} & Analfabetos/as y primarios incompletos & 31,4 & 48,0 & 54,2 & +-- & "--- & ב--- \\
\hline & Educación primaria & 57,1 & 69,5 & 78,4 & 46,4 & 61,8 & 70,9 \\
\hline & $1^{\text {a }}$ etapa de ed. secundaria & 87,3 & 92,1 & 94,6 & 80,9 & 86,1 & 91,3 \\
\hline & $2^{\mathrm{a}}$ etapa de ed. secundaria & 96,0 & 96,7 & 98,3 & 92,6 & 93,9 & 96,4 \\
\hline & FP grado superior & 97,9 & 98,6 & 99,1 & 95,5 & 96,5 & 97,8 \\
\hline & Educación superior universitaria & 98,8 & 99,2 & 99,6 & 97,4 & 97,7 & 98,8 \\
\hline \multirow{7}{*}{$\begin{array}{c}\text { Tamaño } \\
\text { hábitat }\end{array}$} & Capitales > 500 mil hab. & 92,5 & 95,9 & 96,7 & 88,6 & 91,9 & 94,3 \\
\hline & Capitales $<500$ mil hab. & 90,1 & 93,4 & 95,2 & 85,1 & 89,7 & 92,6 \\
\hline & Municipios > 100 mil hab. & 86,6 & 92,9 & 93,8 & 81,6 & 89,4 & 91,7 \\
\hline & Municipios de 50 a 100 mil hab. & 87,1 & 93,2 & 95,7 & 83,2 & 90,0 & 93,7 \\
\hline & Municipios de 20 a 50 mil hab. & 86,3 & 89,7 & 93,3 & 82,0 & 85,8 & 90,1 \\
\hline & Municipios de 10 a 20 mil hab. & 86,3 & 88,8 & 92,9 & 81,7 & 84,5 & 89,5 \\
\hline & Municipios < 10 mil hab. & 82,3 & 88,3 & 90,7 & 76,3 & 83,7 & 87,7 \\
\hline \multirow{6}{*}{$\begin{array}{l}\text { Renta neta } \\
\text { por hogar }\end{array}$} & Menos de 900 euros & 76,8 & 81,2 & 86,2 & 68,9 & 75,4 & 81,1 \\
\hline & De 901 a 1.600 euros & 83,6 & 89,4 & 92,5 & 77,9 & 84,6 & 89,6 \\
\hline & De 1.601 a 2.500 euros & 92,1 & 96,1 & 97,1 & 89,4 & 93,7 & 94,7 \\
\hline & De 2.501 a 3.000 euros & 97,6 & 97,9 & 98,8 & 95,8 & 95,8 & 98,1 \\
\hline & Más de 3.000 euros & 97,9 & 98,7 & 99,2 & 96,8 & 97,2 & 98,5 \\
\hline & Ns/Nc & 87,0 & 91,8 & 93,2 & 81,4 & 87,0 & 90,1 \\
\hline \multirow{5}{*}{ Estado civil } & Soltero/a & 95,0 & 95,7 & 97,1 & 92,0 & 93,6 & 95,8 \\
\hline & Casado/a & 83,7 & 89,6 & 92,5 & 78,0 & 84,6 & 89,1 \\
\hline & Viudo/a & 58,4 & 69,4 & 76,5 & 50,8 & 62,6 & 71,2 \\
\hline & Separado/a & 80,0 & 89,1 & 92,2 & 73,1 & 84,2 & 87,4 \\
\hline & Divorciado/a & 91,7 & 96,0 & 95,4 & 86,3 & 91,0 & 92,0 \\
\hline \multirow{6}{*}{ Tipo de hogar } & Hogar unipersonal & ב--- & ב--- & 89,1 & ב--- & 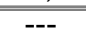 & 84,3 \\
\hline & Padre o madre solo/a que conviva con algún hijo & --- & --- & 93,7 & --- & --- & 92,0 \\
\hline & Pareja sin hijos que conviva en el hogar & --- & --- & 87,3 & --- & --- & 82,8 \\
\hline & Pareja con hijos que conviva en el hogar & --- & --- & 97,7 & --- & --- & 96,2 \\
\hline & Otro tipo de hogar & --- & --- & 92,6 & --- & --- & 88,0 \\
\hline & Total indiv. (16 a 74 años) & 87,3 & 91,6 & 94,0 & 82,5 & 87,7 & 91,3 \\
\hline
\end{tabular}




\begin{tabular}{|c|c|c|c|c|c|c|c|}
\hline & \multirow[b]{2}{*}{$\%$ de individuos } & \multicolumn{3}{|c|}{ Internautas (\%) } & \multicolumn{3}{|c|}{ Internautas acceso semanal (\%) } \\
\hline & & 2018 & 2019 & 2020 & 2018 & 2019 & 2020 \\
\hline \multirow{2}{*}{ Género } & Hombre & 49,9 & 49,7 & 49,7 & 49,9 & 49,4 & 49,5 \\
\hline & Mujer & 50,1 & 50,3 & 50,3 & 50,1 & 50,6 & 50,5 \\
\hline \multirow{6}{*}{ Edad } & De 16 a 24 años & 13,2 & 12,9 & 13,0 & 13,8 & 13,4 & 13,4 \\
\hline & De 25 a 34 años & 17,2 & 16,2 & 15,8 & 17,9 & 16,8 & 16,2 \\
\hline & De 35 a 44 años & 24,0 & 22,5 & 21,5 & 24,9 & 23,0 & 21,9 \\
\hline & De 45 a 54 años & 22,3 & 22,2 & 22,2 & 22,4 & 22,2 & 22,4 \\
\hline & De 55 a 64 años & 15,4 & 16,7 & 17,4 & 14,5 & 16,0 & 16,9 \\
\hline & De 65 a 74 años & 7,9 & 9,5 & 10,1 & 6,7 & 8,6 & 9,3 \\
\hline \multirow{7}{*}{$\begin{array}{c}\text { Situación } \\
\text { Laboral }\end{array}$} & Población ocupada por cuenta ajena & 49,2 & 48,3 & 43,2 & 50,7 & 49,2 & 43,9 \\
\hline & Población ocupada por cuenta propia & 9,2 & 9,1 & 8,1 & 9,3 & 9,1 & 8,1 \\
\hline & Población activa parada & 13,7 & 12,5 & 16,0 & 13,5 & 12,3 & 16,1 \\
\hline & Estudiante & 10,2 & 10,6 & 10,6 & 10,6 & 11,0 & 10,9 \\
\hline & Labores del hogar & 5,0 & 5,1 & 4,2 & 4,6 & 5,0 & 4,1 \\
\hline & Pensionista & 8,7 & 10,1 & 10,5 & 7,5 & 9,2 & 9,6 \\
\hline & Otra situación laboral & 4,1 & 4,4 & 7,3 & 3,8 & 4,2 & 7,3 \\
\hline \multirow{6}{*}{$\begin{array}{l}\text { Estudios } \\
\text { Terminados }\end{array}$} & Analfabetos/as y primarios incompletos & 1,5 & 2,0 & 2,1 & 1,1 & 1,8 & 1,9 \\
\hline & Educación primaria & 7,8 & 7,5 & 9,4 & 6,7 & 7,0 & 8,8 \\
\hline & $1^{a}$ etapa de ed. secundaria & 26,0 & 26,8 & 23,3 & 25,4 & 26,2 & 23,2 \\
\hline & $2^{\text {a }}$ etapa de ed. secundaria & 25,8 & 25,4 & 26,1 & 26,3 & 25,7 & 26,4 \\
\hline & FP grado superior & 12,4 & 12,2 & 12,5 & 12,8 & 12,5 & 12,7 \\
\hline & Educación superior universitaria & 26,4 & 26,0 & 26,4 & 27,5 & 26,7 & 27,0 \\
\hline \multirow{7}{*}{$\begin{array}{c}\text { Tamaño } \\
\text { hábitat }\end{array}$} & Capitales > 500 mil hab. & 16,7 & 16,1 & 16,3 & 16,9 & 16,1 & 16,3 \\
\hline & Capitales $<500$ mil hab. & 16,4 & 16,0 & 16,1 & 16,4 & 16,1 & 16,2 \\
\hline & Municipios > 100 mil hab. & 10,3 & 10,7 & 10,5 & 10,3 & 10,7 & 10,6 \\
\hline & Municipios de 50 a 100 mil hab. & 12,1 & 12,7 & 12,9 & 12,2 & 12,8 & 13,0 \\
\hline & Municipios de 20 a 50 mil hab. & 15,3 & 15,0 & 15,1 & 15,4 & 15,0 & 15,1 \\
\hline & Municipios de 10 a 20 mil hab. & 11,3 & 11,0 & 11,1 & 11,3 & 10,9 & 11,0 \\
\hline & Municipios < 10 mil hab. & 18,0 & 18,5 & 18,0 & 17,6 & 18,3 & 17,9 \\
\hline \multirow{6}{*}{$\begin{array}{l}\text { Renta neta } \\
\text { por hogar }\end{array}$} & Menos de 900 euros & 13,1 & 12,7 & 12,1 & 12,4 & 12,3 & 11,7 \\
\hline & De 901 a 1.600 euros & 26,9 & 28,9 & 28,1 & 26,5 & 28,6 & 28,0 \\
\hline & De 1.601 a 2.500 euros & 19,5 & 20,6 & 19,3 & 20,0 & 21,0 & 19,4 \\
\hline & De 2.501 a 3.000 euros & 7,8 & 7,9 & 8,3 & 8,1 & 8,1 & 8,5 \\
\hline & Más de 3.000 euros & 10,8 & 11,5 & 12,5 & 11,3 & 11,8 & 12,8 \\
\hline & Ns/Nc & 22,0 & 18,5 & 19,7 & 21,7 & 18,3 & 19,6 \\
\hline \multirow{5}{*}{ Estado civil } & Soltero/a & 38,7 & 39,5 & 39,4 & 39,6 & 40,4 & 40,0 \\
\hline & Casado/a & 53,0 & 51,6 & 51,8 & 52,3 & 50,9 & 51,3 \\
\hline & Viudo/a & 1,9 & 2,1 & 2,3 & 1,8 & 2,0 & 2,2 \\
\hline & Separado/a & 1,6 & 1,7 & 1,3 & 1,5 & 1,6 & 1,3 \\
\hline & Divorciado/a & 4,8 & 5,1 & 5,2 & 4,8 & 5,0 & 5,2 \\
\hline \multirow{5}{*}{ Tipo de hogar } & Hogar unipersonal & +--- & --- & 9,1 & --- & ---- & 8,9 \\
\hline & Padre o madre solo/a que conviva con algún hijo & --- & --- & 13,5 & --- & --- & 13,7 \\
\hline & Pareja sin hijos que conviva en el hogar & --- & --- & 16,0 & --- & --- & 15,6 \\
\hline & Pareja con hijos que conviva en el hogar & --- & --- & 50,1 & --- & --- & 50,8 \\
\hline & Otro tipo de hogar & --- & --- & 11,2 & --- & --- & 11,0 \\
\hline & Total & 100,0 & 100,0 & 100,0 & 100,0 & 100,0 & 100,0 \\
\hline
\end{tabular}




\begin{tabular}{|c|c|c|c|c|c|c|c|}
\hline & & \multicolumn{3}{|c|}{ Internautas (millones) } & \multicolumn{3}{|c|}{ Internautas acceso semanal (millones) } \\
\hline & & 2018 & 2019 & 2020 & 2018 & 2019 & 2020 \\
\hline \multirow{2}{*}{ Género } & Hombre & 15,083 & 15,885 & 16,451 & 14,264 & 15,128 & 15,920 \\
\hline & Mujer & 15,141 & 16,103 & 16,661 & 14,316 & 15,491 & 16,236 \\
\hline \multirow{6}{*}{ Edad } & De 16 a 24 años & 3,998 & 4,116 & 4,297 & 3,998 & 4,088 & 4,294 \\
\hline & De 25 a 34 años & 5,207 & 5,190 & 5,232 & 5,207 & 5,156 & 5,217 \\
\hline & De 35 a 44 años & 7,265 & 7,193 & 7,118 & 7,265 & 7,043 & 7,027 \\
\hline & De 45 a 54 años & 6,726 & 7,101 & 7,356 & 6,726 & 6,792 & 7,210 \\
\hline & De 55 a 64 años & 4,642 & 5,356 & 5,750 & 4,642 & 4,906 & 5,428 \\
\hline & De 65 a 74 años & 2,387 & 3,032 & 3,360 & 2,387 & 2,636 & 2,981 \\
\hline \multirow{7}{*}{$\begin{array}{c}\text { Situación } \\
\text { Laboral }\end{array}$} & Población ocupada por cuenta ajena & 14,872 & 15,450 & 14,314 & 14,489 & 15,064 & 14,123 \\
\hline & Población ocupada por cuenta propia & 2,766 & 2,899 & 2,673 & 2,644 & 2,800 & 2,605 \\
\hline & Población activa parada & 4,143 & 4,002 & 5,310 & 3,854 & 3,778 & 5,173 \\
\hline & Estudiante & 3,073 & 3,377 & 3,514 & 3,032 & 3,362 & 3,514 \\
\hline & Labores del hogar & 1,509 & 1,646 & 1,394 & 1,306 & 1,530 & 1,308 \\
\hline & Pensionista & 2,633 & 3,221 & 3,492 & 2,157 & 2,812 & 3,090 \\
\hline & Otra situación laboral & 1,228 & 1,393 & 2,415 & 1,098 & 1,274 & 2,344 \\
\hline \multirow{7}{*}{$\begin{array}{l}\text { Estudios } \\
\text { Terminados }\end{array}$} & Analfabetos/as y primarios incompletos & 0,448 & 0,649 & 0,701 & 0,310 & 0,546 & 0,606 \\
\hline & Educación primaria & 2,352 & 2,408 & 3,115 & 1,912 & 2,141 & 2,816 \\
\hline & $1^{a}$ etapa de ed. secundaria & 7,845 & 8,567 & 7,727 & 7,265 & 8,018 & 7,454 \\
\hline & $2^{\mathrm{a}}$ etapa de ed. secundaria & 7,786 & 8,111 & 8,646 & 7,513 & 7,872 & 8,480 \\
\hline & FP grado superior & 3,744 & 3,915 & 4,139 & 3,652 & 3,833 & 4,085 \\
\hline & Educación superior universitaria & 7,969 & 8,303 & 8,740 & 7,860 & 8,175 & 8,672 \\
\hline & No se puede codificar & 0,080 & 0,036 & 0,045 & 0,067 & 0,035 & 0,044 \\
\hline \multirow{7}{*}{$\begin{array}{l}\text { Tamaño } \\
\text { hábitat }\end{array}$} & Capitales > 500 mil hab. & 5,043 & 5,151 & 5,388 & 4,830 & 4,937 & 5,253 \\
\hline & Capitales < 500 mil hab. & 4,967 & 5,123 & 5,347 & 4,690 & 4,923 & 5,197 \\
\hline & Municipios > 100 mil hab. & 3,116 & 3,414 & 3,486 & 2,936 & 3,288 & 3,406 \\
\hline & Municipios de 50 a $100 \mathrm{mil} \mathrm{hab}$ & 3,644 & 4,054 & 4,262 & 3,482 & 3,915 & 4,175 \\
\hline & Municipios de 20 a 50 mil hab. & 4,624 & 4,813 & 5,016 & 4,392 & 4,606 & 4,843 \\
\hline & Municipios de 10 a 20 mil hab. & 3,402 & 3,525 & 3,660 & 3,219 & 3,353 & 3,526 \\
\hline & Municipios < 10 mil hab. & 5,429 & 5,909 & 5,954 & 5,030 & 5,598 & $\begin{array}{l}3,720 \\
5,756\end{array}$ \\
\hline \multirow{6}{*}{$\begin{array}{l}\text { Renta neta } \\
\text { por hogar }\end{array}$} & Menos de 900 euros & 3,957 & 4,052 & 3,997 & 3,548 & 3,762 & 3,758 \\
\hline & De 901 a 1.600 euros & 8,131 & 9,240 & 9,308 & 7,571 & 8,745 & 9,012 \\
\hline & De 1.601 a 2.500 euros & 5,880 & 6,602 & 6,398 & 5,708 & 6,431 & 6,239 \\
\hline & De 2.501 a 3.000 euros & 2,366 & 2,525 & 2,762 & 2,324 & 2,471 & 2,741 \\
\hline & Más de 3.000 euros & 3,253 & 3,666 & 4,135 & 3,217 & 3,613 & 4,109 \\
\hline & Ns/Nc & 6,637 & 5,904 & 6,512 & 6,213 & 5,597 & 6,297 \\
\hline \multirow{5}{*}{ Estado civil } & Soltero/a & 11,690 & 12,637 & 13,050 & 11,327 & 12,369 & 12,874 \\
\hline & Casado/a & 16,029 & 16,505 & 17,154 & 14,951 & 15,585 & 16,510 \\
\hline & Viudo/a & 0,587 & 0,681 & 0,747 & 0,510 & 0,615 & 0,696 \\
\hline & Separado/a & 0,476 & 0,534 & 0,433 & 0,435 & 0,505 & 0,410 \\
\hline & Divorciado/a & 1,442 & 1,631 & 1,728 & 1,358 & 1,546 & 1,666 \\
\hline \multirow{6}{*}{ Tipo de hogar } & Hogar unipersonal & $-\ldots$ & --- & 3,011 & $\ldots$ & $-\ldots-$ & 2,848 \\
\hline & Padre o madre solo/a que conviva con algún hijo & --- & --- & 4,482 & --- & --- & 4,398 \\
\hline & Pareja sin hijos que conviva en el hogar & --- & --- & 5,300 & --- & --- & 5,030 \\
\hline & Pareja con hijos que conviva en el hogar & --- & --- & 16,596 & --- & --- & 16,344 \\
\hline & Otro tipo de hogar & --- & --- & 3,723 & --- & --- & 3,535 \\
\hline & Total indiv. (16 a 74 años) & 30,224 & 31,988 & 33,112 & 28,580 & 30,620 & 32,156 \\
\hline
\end{tabular}




\begin{tabular}{|c|c|c|c|c|c|c|c|}
\hline & & \multicolumn{3}{|c|}{ Población total (16 a 74 años) (millones) } & \multicolumn{3}{|c|}{ Población total (16 a 74 años) (\%) } \\
\hline & & 2018 & 2019 & 2020 & 2018 & 2019 & 2020 \\
\hline \multirow{2}{*}{ Género } & Hombre & 17,188 & 17,316 & 17,473 & 49,6 & 49,6 & 49,6 \\
\hline & Mujer & 17,451 & 17,594 & 17,766 & 50,4 & 50,4 & 50,4 \\
\hline \multirow{6}{*}{ Edad } & De 16 a 24 años & 4,058 & 4,148 & 4,305 & 11,7 & 11,9 & 12,2 \\
\hline & De 25 a 34 años & 5,314 & 5,290 & 5,249 & 15,3 & 15,2 & 14,9 \\
\hline & De 35 a 44 años & 7,479 & 7,354 & 7,163 & 21,6 & 21,1 & 20,3 \\
\hline & De 45 a 54 años & 7,349 & 7,452 & 7,557 & 21,2 & 21,3 & 21,4 \\
\hline & De 55 a 64 años & 5,931 & 6,100 & 6,325 & 17,1 & 17,5 & 18,0 \\
\hline & De 65 a 74 años & 4,508 & 4,566 & 4,639 & 13,0 & 13,1 & 13,2 \\
\hline \multirow{7}{*}{$\begin{array}{c}\text { Situación } \\
\text { Laboral }\end{array}$} & Población ocupada por cuenta ajena & 15,480 & 15,767 & 14,455 & 44,7 & 45,2 & 41,0 \\
\hline & Población ocupada por cuenta propia & 2,997 & 2,987 & 2,726 & 8,7 & 8,6 & 7,7 \\
\hline & Población activa parada & 4,576 & 4,304 & 5,508 & 13,2 & 12,3 & 15,6 \\
\hline & Estudiante & 3,088 & 3,391 & 3,514 & 8,9 & 9,7 & 10,0 \\
\hline & Labores del hogar & 2,426 & 2,223 & 1,654 & 7,0 & 6,4 & 4,7 \\
\hline & Pensionista & 4,399 & 4,462 & 4,659 & 12,7 & 12,8 & 13,2 \\
\hline & Otra situación laboral & 1,672 & 1,776 & 2,722 & 4,8 & 5,1 & 7,7 \\
\hline \multirow{7}{*}{$\begin{array}{l}\text { Estudios } \\
\text { Terminados }\end{array}$} & Analfabetos/as y primarios incompletos & 1,427 & 1,353 & 1,293 & 4,1 & 3,9 & 3,7 \\
\hline & Educación primaria & 4,120 & 3,466 & 3,974 & 11,9 & 9,9 & 11,3 \\
\hline & $1^{\mathrm{a}}$ etapa de ed. secundaria & 8,982 & 9,307 & 8,166 & 25,9 & 26,7 & 23,2 \\
\hline & $2^{a}$ etapa de ed. secundaria & 8,111 & 8,386 & 8,798 & 23,4 & 24,0 & 25,0 \\
\hline & FP grado superior & 3,823 & 3,971 & 4,177 & 11,0 & 11,4 & 11,9 \\
\hline & Educación superior universitaria & 8,067 & 8,367 & 8,776 & 23,3 & 24,0 & 24,9 \\
\hline & No se puede codificar & 0,110 & 0,062 & 0,055 & 0,3 & 0,2 & 0,2 \\
\hline \multirow{7}{*}{$\begin{array}{r}\text { Tamaño } \\
\text { hábitat }\end{array}$} & Capitales > 500 mil hab. & 5,450 & 5,373 & 5,573 & 15,7 & 3,9 & 15,8 \\
\hline & Capitales < 500 mil hab. & 5,513 & 5,487 & 5,614 & 15,9 & 9,9 & 15,9 \\
\hline & Municipios > 100 mil hab. & 3,600 & 3,677 & 3,715 & 10,4 & 26,7 & 10,5 \\
\hline & Municipios de 50 a 100 mil hab. & 4,184 & 4,350 & 4,455 & 12,1 & 24,0 & 12,6 \\
\hline & Municipios de 20 a 50 mil hab. & 5,355 & 5,367 & 5,377 & 15,5 & 11,4 & 15,3 \\
\hline & Municipios de 10 a 20 mil hab. & 3,942 & 3,969 & 3,940 & 11,4 & 24,0 & 11,2 \\
\hline & Municipios $<10$ mil hab. & 6,596 & 6,689 & 6,564 & 19,0 & 0,2 & 18,6 \\
\hline \multirow{6}{*}{$\begin{array}{l}\text { Renta neta } \\
\text { por hogar }\end{array}$} & Menos de 900 euros & 5,151 & 4,987 & 4,634 & 14,9 & 14,3 & 13,2 \\
\hline & De 901 a 1.600 euros & 9,724 & 10,331 & 10,060 & 28,1 & 29,6 & 28,5 \\
\hline & De 1.601 a 2.500 euros & 6,383 & 6,867 & 6,591 & 18,4 & 19,7 & 18,7 \\
\hline & De 2.501 a 3.000 euros & 2,425 & 2,579 & 2,796 & 7,0 & 7,4 & 7,9 \\
\hline & Más de 3.000 euros & 3,324 & 3,716 & 4,170 & 9,6 & 10,6 & 11,8 \\
\hline & Ns/Nc & 7,632 & 6,430 & 6,988 & 22,0 & 18,4 & 19,8 \\
\hline \multirow{5}{*}{ Estado civil } & Soltero/a & 12,308 & 13,208 & 13,442 & 35,5 & 37,8 & 38,1 \\
\hline & Casado/a & 19,158 & 18,423 & 18,539 & 55,3 & 52,8 & 52,6 \\
\hline & Viudo/a & 1,005 & 0,982 & 0,977 & 2,9 & 2,8 & 2,8 \\
\hline & Separado/a & 0,595 & 0,600 & 0,469 & 1,7 & 1,7 & 1,3 \\
\hline & Divorciado/a & 1,573 & 1,698 & 1,811 & 4,5 & 4,9 & 5,1 \\
\hline \multirow{5}{*}{ Tipo de hogar } & Hogar unipersonal & ב-- & "--- & 3,381 & 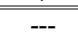 & ב--- & 9,6 \\
\hline & Padre o madre solo/a que conviva con algún hijo & --- & -- & 4,781 & --- & --- & 13,6 \\
\hline & Pareja sin hijos que conviva en el hogar & --- & --- & 6,073 & --- & --- & 17,2 \\
\hline & Pareja con hijos que conviva en el hogar & --- & -- & 16,984 & --- & --- & 48,2 \\
\hline & Otro tipo de hogar & $-\ldots$ & --- & 4,019 & --- & --- & 11,4 \\
\hline
\end{tabular}




\section{Universo}

Hogares (con algún miembro de 16 a 74 años): 15,65 millones. Ámbito, todo el territorio nacional Individuos: 35,23 millones de 16 a 74 años

El estudio hace referencia a la población de 16 a 74 años

\section{Muestra}

Hogares (16-74 años): 12.621 viviendas

En cada hogar se encuesta aleatoriamente a un miembro de 16 o más años y a todos los niños/as entre 10 y 15 años.

\section{Metodología}

Para obtener la información sobre la metodología de la encuesta (diseño muestral, trabajo de campo, errores muestrales, cuestionarios,...) consultar en:

https://www.ine.es/dyngs/INEbase/es/operacion.htm?c=Estadistica C\&cid=1254736176741\&menu=metodologia\&idp=1254 $\underline{735976608}$

El estudio, se realiza procesando los microdatos de la encuesta TIC-H del INE, gracias al convenio de colaboración con el Instituto Nacional de Estadística (INE).

Por otro lado, como novedad este año, el INE incluye distintos apartados dedicados a la privacidad y protección de datos personales; confianza, seguridad y privacidad en Internet así como Internet de las cosas (loT), incluido en el punto 5 de este informe. 
El informe del "Perfil sociodemográfico de los internautas. Análisis de datos INE 2020" ha sido elaborado por el siguiente equipo de trabajo del Observatorio Nacional de Tecnología y Sociedad (ONTSI) de Red.es:

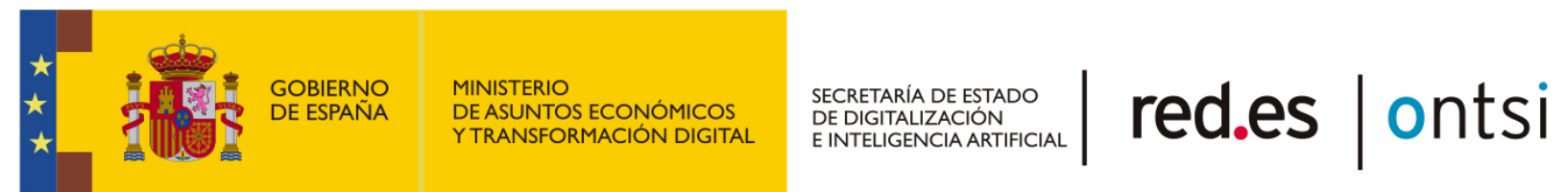
Lucía Velasco
Alberto Urueña
Raquel Castro García-Muñoz
Santiago Cadenas Villaverde
José Antonio Seco Arnegas

ISSN 2172-9212

DOI : $10.30923 /$ PerSocInt-2020

NIPO:094-21-067-8

Reservados todos los derechos. Se permite su copia y distribución por cualquier medio siempre que se mantenga el reconocimiento de sus autores, no se haga uso comercial de las obras y no se realice ninguna modificación de las mismas 